\title{
Nuclear entry, oligomerization, and DNA binding of the Drosophila heat shock transcription factor are regulated by a unique nuclear localization sequence
}

\author{
Ebrahim Zandi, ${ }^{1}$ Thanh-Nga T. Tran, Winston Chamberlain, and Carl S. Parker ${ }^{2}$ \\ Division of Chemistry and Chemical Engineering, California Institute of Technology, Pasadena, California 91125 USA
}

In normally growing Drosophila cultured cells the Drosophila heat shock transcription factor (dHSF) is localized in the cytosol and translocates into the nucleus after heat shock. In the cytosol of nonshocked cells, the dHSF is present as a monomer that cannot bind DNA. Upon stress, the dHSF enters the nucleus where it is observed to be a trimer. A novel nuclear localization sequence (NLS) in the dHSF was found to be responsible for stress-dependent nuclear entry. Deletion of the NLS prevents nuclear entry, as expected, yet surprisingly also allows constitutive oligomerization and DNA binding in the cytosol. Further analysis of the NLS by mutagenesis suggests that the two functions of nuclear entry and oligomerization are separable in that distinct residues present in the NLS are responsible for each. Mutations in certain basic residues completely block nuclear entry, as expected for a constitutive NLS. In addition, two residues were found in the NLS that, when altered, allowed constitutive nuclear entry of dHSF independent of stress. These residues may interact with a putative cellular component or possibly other domains of the HSF to prevent nuclear entry in normally growing cells. The NLS can also function autonomously to target a $\beta$-galactosidase fusion protein into the nucleus in a heat shock-dependent fashion.

[Key Words: Transcription regulation; nuclear localization, DNA-binding regulation]

Received November 25, 1996; revised version accepeted March 21, 1997.

The activity of specific transcription factors can be regulated at several levels, including DNA binding and transcription activation (Keegan et al. 1986; for review, see Ptashne 1988). Regulation of DNA binding is often the result of cytoplasmic sequestration through association with other proteins (for review, see Baeuerle and Henkel 1994). For example, steroid receptors are localized in the cytoplasm in association with other proteins that restrict their entry into the nucleus (Picard and Yamamoto 1987; for review, see Hanover 1992). When the appropriate hormone ligand is present, these complexes are disrupted and the receptor can enter the nucleus to activate transcription (Picard and Yamamoto 1987). Similarly, the NF- $\mathrm{BB} / \mathrm{rel} /$ dorsal family of transcription factors is tethered in the cytosol by association with $I_{\kappa} B$ proteins (Baeuerle and Baltimore 1988; Steward 1989; Beg et al. 1992; for review, see Blank et al. 1992; Baeuerle and Henkel 1994). In response to the appropriate stimulus, ІкB

${ }^{1}$ Present address: Department of Pharmacology, School of Medicine, Center for Molecular Genetics, University of California, San Diego, La Jolla, California 92093-0636.

${ }^{2}$ Corresponding author.

E-MAIL csp@cco.caltech.edu; FAX (818) 568-9430. becomes phosphorylated and degraded, allowing NF-кB to enter the nucleus (Henkel et al. 1993; Beg and Baldwin 1994).

Another interesting example of signal-induced transcription factor activation is the heat shock transcription factor (HSF). The activity of the HSF from various organisms from yeast to man is regulated by heat and other stressors (for review, see Morimoto et al. 1992; Voellmy 1994). HSF activation in insects and vertebrates is thought to include a monomer to trimer transition and, in the case of vertebrates, stress-dependent nuclear localization (Clos et al. 1990; Baler et al. 1993; Sarge et al. 1993; for review, see Voellmy 1994). With regard to the Drosophila HSF (dHSF), earlier reports suggested a potentially more complex situation. Biochemical fractionation studies showed that the dHSF is present in the cytosol as a monomer in nonshocked cells /Clos et al. 1990). Indirect immunocytological staining showed, however, that the factor is present in the nucleus in both nonshocked and heat-shocked cells (Westwood et al. 1991).

Despite the conserved function of the HSF in eukaryotes, there is little overall protein sequence homology. For example, all HSFs from yeast to man bind efficiently 
to the highly conserved heat shock response elements (HSE), which consist of an array of nGAAn repeats; yet they share only $-30 \%$ amino acid homology in the DNAbinding domain (Sorger and Pelham 1988; Wiederecht et al. 1988; Clos et al. 1990; Scharff et al. 1990; Gallo et al. 1991; Rabindran et al. 1991; Sarge et al. 1991; Schuetz et al. 1991). A second region of homology includes a conserved heptad leucine-isoleucine repeat (LIR), which is responsible for the oligomerization of the factor and is adjacent to the DNA-binding domain (Sorger and Nelson 1989). Vertebrate, Drosophila, and plant HSFs all contain a third region of homology, which is also an LIR at the carboxyl terminus (Clos et al. 1990; Scharff et al. 1990; Gallo et al. 1991; Rabindran et al. 1991; Sarge et al. 1991; Schuetz et al. 1991). The ScHSF does not possess this third homology region and binds constitutively to DNA (Jakobsen and Pelham 1988; Sorger et al. 1988; Wiederecht et al. 1988). This fact raises the interesting possibility that the third LIR might be involved in regulation of the stress-induced monomer-to-trimer transition observed in Drosophila and vertebrate HSFs. Mutations in three conserved hydrophobic amino acids within the carboxy-terminal LIR of the human HSF (hHSF) and deletion of the homologous region in the dHSF resulted in constitutive trimerization and DNA binding of these factors when assayed in whole-cell extracts of transiently transfected cells (Rabindran et al. 1993).

In this report we describe the identification and characterization of the nuclear localization sequence (NLS) domain of the dHSF that is essential for stress-dependent regulation of nuclear localization, oligomerization, and DNA binding in Drosophila SL2 cells. The NLS also responds to stress when placed in the context of another protein, suggesting that it may function autonomously. Furthermore, we show that cytoplasmic sequestration of the dHSF in nonshocked cells is saturable and can be overcome by high levels of protein expression, leading to the interesting prospect that a limiting cytosolic component may be responsible for sequestration.

\section{Results}

\section{dHSF nuclear entry is regulated by stress}

In Drosophila, biochemical fractionation studies of SL2 cells have shown that the dHSF is found in the cytosol of normally growing cells; this is also true for exogenously expressed vertebrate HSF in these cells (Clos et al. 1990; Westwood et al. 1991; Baler et al. 1993; Sarge et al. 1993). Immunocytochemical studies of nonstressed HeLa cells and mouse $3 \mathrm{~T} 3$ fibroblasts have shown that HSF1 is distributed in a diffuse pattern over the cytoplasm and nucleus (Sarge et al. 1993). Upon heat shock, HSF1 enters the nucleus of both 3T3 and HeLa cells /Sarge et al. 1993). In the case of dHSF, however, the immunocytochemical studies performed with Drosophila SL2 cells demonstrate that the factor is localized within the nucleus under all growth conditions, differing from the cell fractionation analysis (Westwood et al. 1991).

The subcellular localization of the dHSF described here is similar to that observed in mammalian cells. A combination of four monoclonal antibodies raised against the recombinant dHSF was used to visualize the subcellular distribution of dHSF in SL2 cells prior to and after heat shock. Shown in Figure 1 (NS) is a representative staining pattern of dHSF localization in nonshocked cells. Figure 1 (NS) shows an apparent perinuclear compartmentalization; in some cells this compartmentalization is clearly localized to one side of the nucleus. A second, less frequent, staining pattern is also observed with dHSF localization distributed evenly between the cytosol and the nucleus, similar to mammalian HSFl.

After 20 min of heat shock, the HSF is no longer observed in the cytosol and nuclear envelope region; it is now localized within the nucleus in a punctate pattern [Fig. 1 (HS)]. The nature and composition of these granules are unknown. This analysis demonstrates that the dHSF is primarily localized in the cytoplasm in SL2 cells growing at normal growth temperatures and suggests
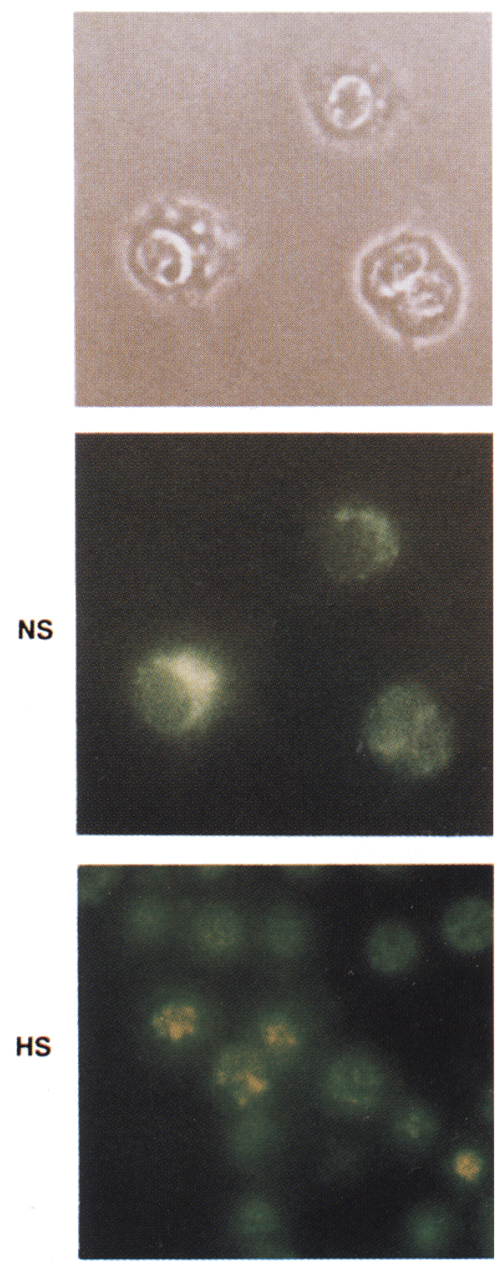

Figure 1. Localization of Drosophila HSF in SL2 cells. This figure shows immunofluorescent photomicrographs positioned below a phase contrast photomicrograph. (NS) Nonshocked cells; (HS) heat-shocked cells. The cells were stained with a 1:100 dilution of anti-dHSF monoclonal antibodies. 
that a stress-regulated NLS domain may exist in the dHSF.

\section{Identification of a stress-regulated NLS in the dHSF}

To identify the NLS of the dHSF, initially we expressed various deletion mutant constructs under the control of the actin 5C promoter in Schneider (SL2) cells. The high levels of expression generated by the actin 5C promoter resulted in constitutive nuclear localization of a significant fraction of the exogenously expressed factors (data not shown). To avoid problems associated with overexpression, we generated SL2 cell lines in which the expression level of the wild-type dHSF and deletion mutants were regulated by the Drosophila metallothionein promoter (see Materials and Methods). Because it is known that high concentrations of heavy metal ions induce the heat shock response (for review, see Morimoto et al. 1992), we determined the concentration range of $\mathrm{CuSO}_{4}$ in which the activity of the endogenous dHSF is regulated properly (Fig. 2). It was found that concentrations of $\mathrm{CuSO}_{4}$ up to $5 \mathrm{~mm}$ and $5 \mathrm{hr}$ of incubation did not induce the endogenous dHSF to bind DNA. In general, 1 hr of incubation with $1 \mathrm{~mm} \mathrm{CuSO}$ provided sufficient levels of exogenous dHSF expression for the purpose of these studies. Under these conditions the exogenous dHSF is expressed at higher levels than the endogenous HSF. This allows one to selectively observe exogenous expression by appropriate dilution of the primary antibody used in Western blotting experiments (see Materials and Methods).

Wild-type exogenous dHSF (construct N691 in Fig. $3 \mathrm{C}, \mathrm{D}, \mathrm{G})$ is distributed evenly over the cytoplasm and nucleus in nonshocked cells (Fig. 3C), and upon heat shock it is localized exclusively in the nucleus (Fig. 3D) in a characteristic punctate pattern. Identical conditions were employed to determine the intracellular localization of 10 HSF deletion mutants and a summary of the results is shown in Figure 3G. Progressive deletion of the dHSF from the carboxyl terminus to amino acid $461 \mathrm{did}$ not alter the subcellular distribution of the factor in either nonshocked or heat-shocked cells (Fig. 3G, constructs N589, N536, and N461).

The subcellular distribution of two internal deletions and one amino terminal-deleted HSF was also examined (Fig. $3 \mathrm{G}$, constructs $\Delta 3 \mathrm{~h}, \Delta \mathrm{Bst}$, and $33 \mathrm{C}$, respectively) and showed staining patterns similar to those of N691 under normal and stressed conditions (Fig. 3G). Removal of the conserved LIR at the carboxy-terminal region (Fig. $3 \mathrm{G}$, construct $\Delta 3 \mathrm{~h}$ ) did not affect the subcellular distribution of the factor in response to stress. Therefore, unlike human HSF2 (Sheldon and Kingston 1993), the LIR does not play an obvious role in regulating the subcellular distribution of dHSF. An internal deletion in the dHSF between amino acids 336 and 403 (Fig. 3G, construct $\Delta$ Saf) and a further deletion from 460 to 404 (Fig. $3 \mathrm{G}$, construct N404), however, resulted in the loss of the nuclear localization in response to heat shock. Further analysis of this region demonstrated that NLS function was localized between amino acids 393 and 420. Deletion of this region (Fig. $3 G$, construct $\triangle N L S$ ) completely blocked nuclear entry of dHSF in response to stress (Fig. $3 \mathrm{E}, \mathrm{F})$. Deletion of sequences 414 to 424 immediately adjacent to the bipartite NLS motif (393 to 414) had no effect on nuclear entry; in addition, none of the dHSF deletion mutations were capable of constitutive nuclear entry (data not shown).

To identify the functional residues present in the NLS

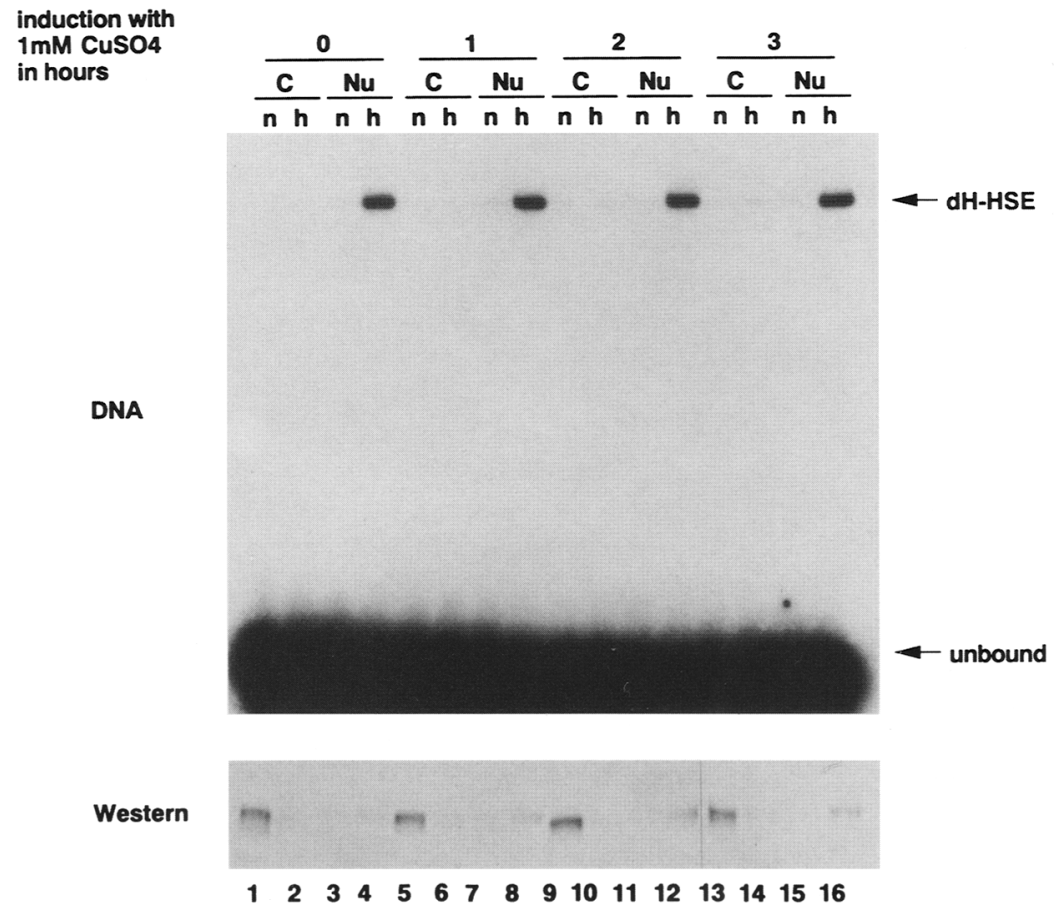

Figure 2. Effect of $\mathrm{CuSO}_{4}$ on endogenous dHSF. Cells were incubated with $1 \mathrm{mM} \mathrm{CuSO}_{4}$ for indicated times in hours and DNA-binding activity (DNA) and subcellular distribution (Western) of endogenous HSF was analyzed in the cytosol (C) and nuclear $(\mathrm{Nu})$ extracts of the nonshocked $(\mathrm{n})$ and heat-shocked (h) cells. 


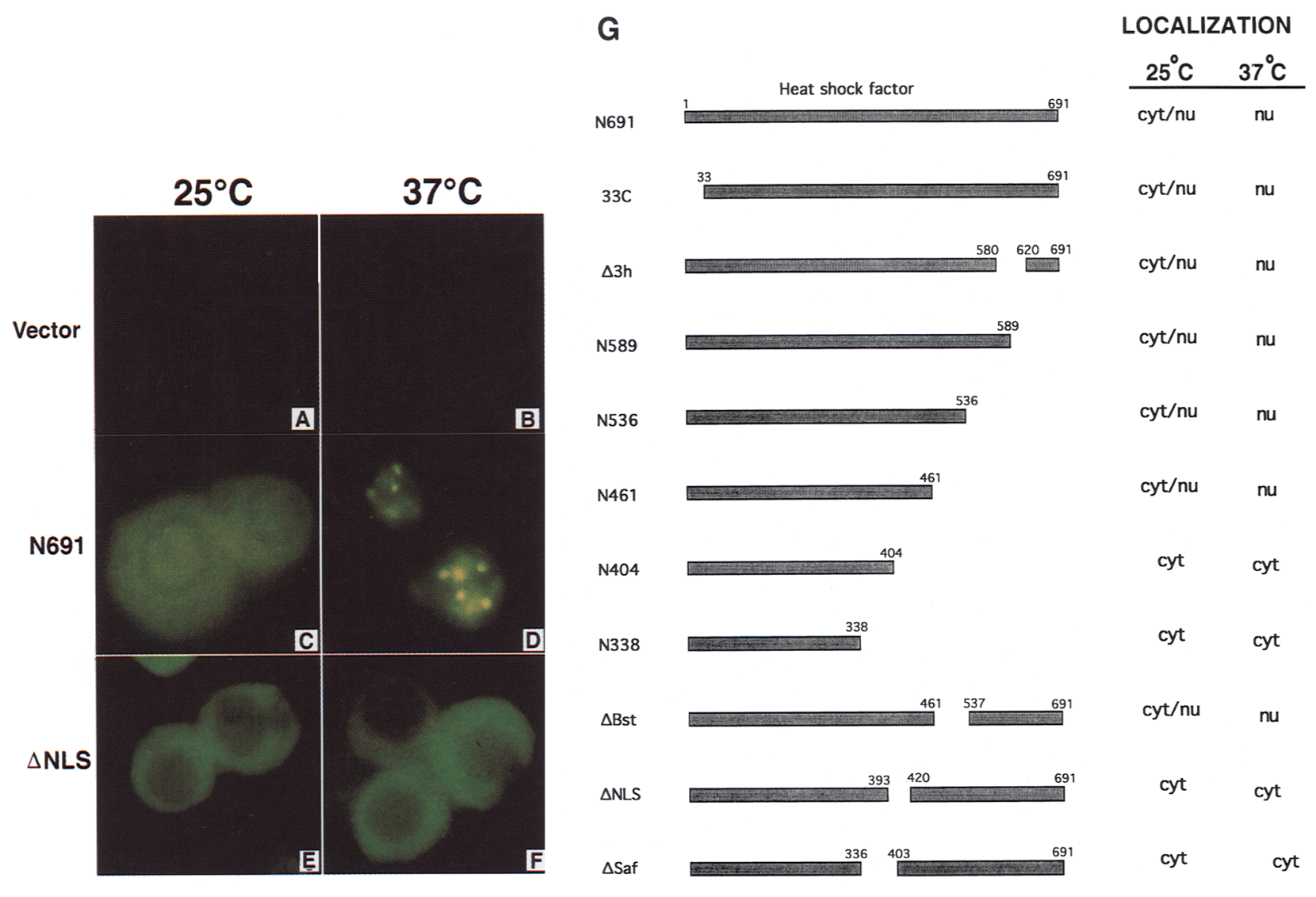

Figure 3. Subcellular distribution of dHSF deletion mutants after transfection into SL2 cells. Immunofluorescence micrographs of nonshocked $\left(25^{\circ} \mathrm{C}\right)$ and heat-shocked SL2 cells $\left(30 \mathrm{~min}\right.$ at $\left.37^{\circ} \mathrm{C}\right)$ in which vector alone $(A, B)$; full-length dHSF (N691) (C,D); NLS deleted dHSF ( $\triangle N L S)(E, F)$ are shown. $(G)$ Summarized results of immunofluorescence analysis of expressed dHSF deletions in SL2 cells. dHSF derivatives are represented schematically by shaded boxes with numbers indicating amino acid positions. (cyt) Staining pattern such as that shown in $E$ or $F$, indicating an exclusively cytoplasmic localization. (nu) Staining pattern as seen in $D$, indicating exclusively nuclear localization. (cyt/nu) Staining pattern such as that shown in $C$, indicating an evenly distributed staining pattern between cytoplasm and nucleus. For each construct, cells were transiently transfected with plasmid DNAs encoding the indicated exogenous factor under control of the metallothionein promoter. Each protein was expressed by induction with $1 \mathrm{mM} \mathrm{CuSO}_{4}$ for $1 \mathrm{hr}$. Exogenous factors were stained with a 1:1000 dilution of the anti-dHSF antibodies (allowing the detection of exogenous factor only).

a random mutagenesis procedure was employed. A group of single and multiple amino acid substitutions in the NLS were isolated as described in Materials and Methods. Stable SL2 cell lines were established that contain internally mutated forms of dHSF under control of the Drosophila metallothionein promoter. Analysis of the subcellular localization of these mutant proteins revealed three classes of mutations (Fig. 4A-N). Mutation of three amino acids [glutamine (Q) 399, lysine (K) 400, and leucine (L) 404] to L, R, and R, respectively, did not alter stress-dependent nuclear entry; however, the process of the nuclear entry was less sensitive to experimental conditions, thus nuclear entry was induced primarily by heat stress (Fig. 4A,B). In addition to heat shock, nuclear localization of this mutant could also be brought about by overexpression (data not shown). At the present time, the LRR mutant is the only example of the class one variant. Class two mutations prevent dHSF nuclear entry under all conditions (Fig. 4C-J). In these mutants, several of the lysine $(\mathrm{K})$ and arginine $(\mathrm{R})$ residues in the
NLS (Fig. 4C-J) are affected. A double substitution of $\mathrm{K}_{400}$ to glutamic acid (E) and $\mathrm{R}_{401}$ to $\mathrm{L}$ resulted in complete impairment of nuclear entry (Fig. 4I,J). Mutation of asparagine $(N) 408$ to serine $(S)$ and $R_{411}$ to $L$ near the carboxyl terminus of the NLS also blocked nuclear entry (Fig. 4G,H). In addition, a single amino acid change from $\mathrm{K}_{405}$ to methionine (M) completely prevented nuclear entry (Fig. 4C,D). One further single amino acid alteration of $\mathrm{L}_{404}$ to proline (P) (Fig. 4E) also prevented nuclear entry, suggesting the structural integrity of the NLS is important for proper function (Fig. 4E,F). All of the class two mutations caused the dHSF to remain in the cytoplasm in a diffuse pattern regardless of growth temperatures. In addition, staining of the nuclear envelope that was observed for the wild-type factor was not observed when these mutations were present. This observation raises the possibility that dHSF interaction with a putative nuclear targeting protein that might concentrate the factor around the nuclear envelope was impaired.

Class three mutations allow constitutive nuclear en- 


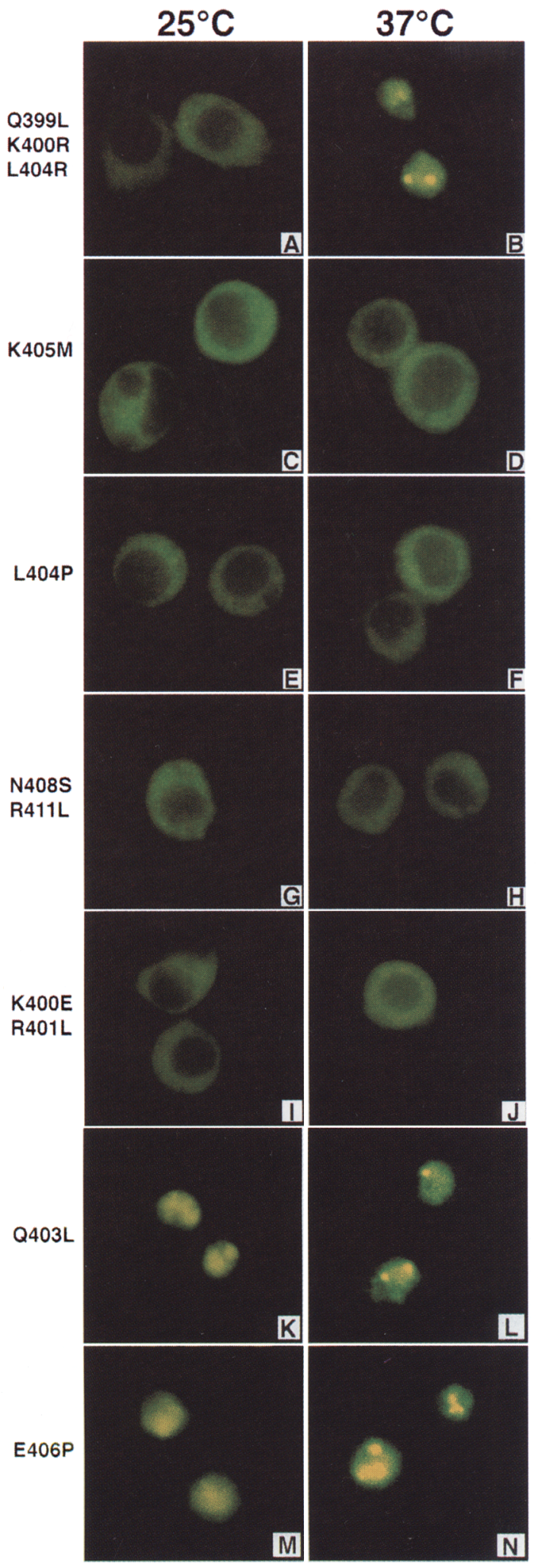

try of the dHSF at normal growth temperatures (Fig. 4KN). The two mutants examined so far are glutamine (Q) 403 to $\mathrm{L}$ and glutamic acid (E) 406 to P. These mutant
Figure 4. Mutational analysis of the NLS. $(A-N)$ Single or mul tiple point mutations were generated as described in Materials and Methods. Each mutant was expressed by addition of $1 \mathrm{~mm}$ $\mathrm{CuSO}_{4}$ for $1 \mathrm{hr}$ to stable cell lines carrying the appropriate constructs under control of the metallothionein promoter. Nonshocked $\left(25^{\circ} \mathrm{C}\right)$ and heat-shocked cells $\left(37^{\circ} \mathrm{C}\right.$ for $\left.30 \mathrm{~min}\right)$ were stained with anti-dHSF antibodies as described in Materials and Methods. Mutant nomenclature: The first letter indicates the wild-type amino acid, the number shows the position, and the second letter is the mutant amino acid. Amino acids are in single-letter code.

dHSFs enter the nucleus constitutively (Fig. 4K,L,M,N for $\mathrm{P}_{406}$, suggesting that residues $\mathrm{Q}_{403}$ and $\mathrm{E}_{406}$ play an important role in retaining the HSF in the cytosol in the absence of stress.

\section{Nuclear localization of $\beta$-galactosidase-HSF fusion proteins}

To determine whether the NLS could regulate the nuclear transport of another protein, the dHSF was fused to Escherichia coli $\beta$-galactosidase. Anti $\beta$-galactosidase antibodies were used to localize the resulting fusion pro-

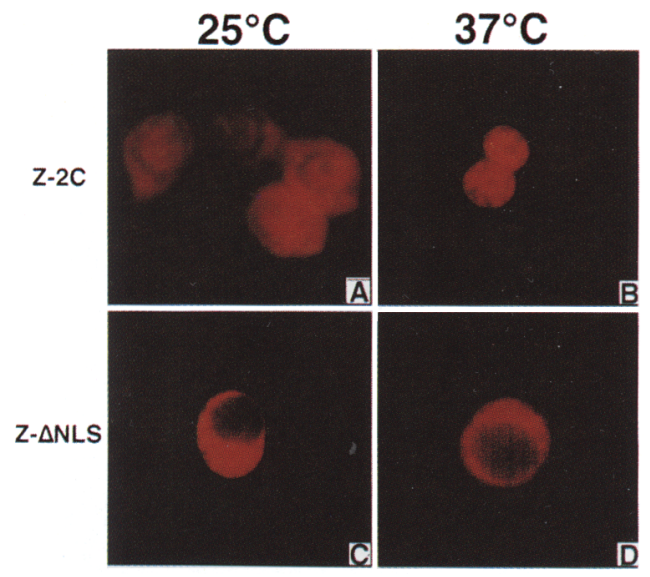

Figure 5. Subcellular distribution of $\beta$-galactosidase-dHSF fusion derivatives. Fusion proteins were expressed in SL2 cells by transfecting them with $0.25 \mu \mathrm{g}$ of plasmid, under control of the actin $5 \mathrm{C}$ promoter. Fusion proteins were visualized in the nonshocked $\left(25^{\circ} \mathrm{C}\right)$ and heat-shocked $\left(30 \mathrm{~min}\right.$ at $\left.37^{\circ} \mathrm{C}\right)$ cells using anti- $\beta$-galactosidase antibodies as described in Materials and Methods. $(A-D)$ Immunofluorescence of representative fusions $\mathrm{Z}-2 \mathrm{C}$ and $\mathrm{Z}-\Delta \mathrm{NLS}$. These results are representative of a number of experiments. In one experiment, for example, of 100 cells analyzed $\sim 60 \%$ of the cells were as shown in $A$ where the fusion protein was distributed uniformly over the nonshocked cells. In the same experiment $\sim 40 \%$ of the cells showed stronger nuclear staining than cytosolic even though they were not heatshocked. We believe that this is attributable to overproduction that occurs when the actin $5 \mathrm{C}$ promoter is used. We used a low amount of plasmid DNA $(0.25 \mu \mathrm{g})$ for the transfections to reduce this effect, but it cannot be completely avoided. 
teins. $\beta$-Galactosidase alone expressed in SL2 cells localizes in the cytosol under normal and heat-shocked conditions (data not shown). Fusions that include the entire HSF (Z-2C) shows a staining pattern very similar to that of the full-length dHSF (N691) (Fig. 5A, nonshocked, B, heat-shocked). The intracellular localization of fusions that include amino acids $165-691$ (Z-165C), 220-691 (Z220C), 360-691 (Z-360C), 2-536 (Z-N536), and 2-460 (Z-N460) were all comparable to the Z-2C fusion under both normal and heat-shocked conditions /data not shown). In contrast, Z- $\Delta$ NLS and all other fusions in which the region between residues 393 and 420 were deleted localize exclusively in the cytosol of both nonshocked and heat-shocked cells (Fig. 5C,D for Z- $\Delta$ NLS; data not shown). These observations support the previous deletion analysis that the region between residues 393 and 420 contains a stress-regulated NLS. It is important to note, however, that high levels of expression of the fusion proteins containing the NLS result in constitutive nuclear localization of a fraction of the expressed fusion protein (data not shown).

To examine whether the region containing the NLS can function autonomously and independently of other HSF sequences, fusion proteins were constructed that join $\beta$-galactosidase and residues $393-424$ of either the wild-type NLS or two singly mutated forms, $\mathrm{K}_{400}$ to $\mathrm{M}$ and $\mathrm{Q}_{403}$ to $\mathrm{L}$. The subcellular distribution of these fusion proteins in SL2 cells was analyzed. The fusion

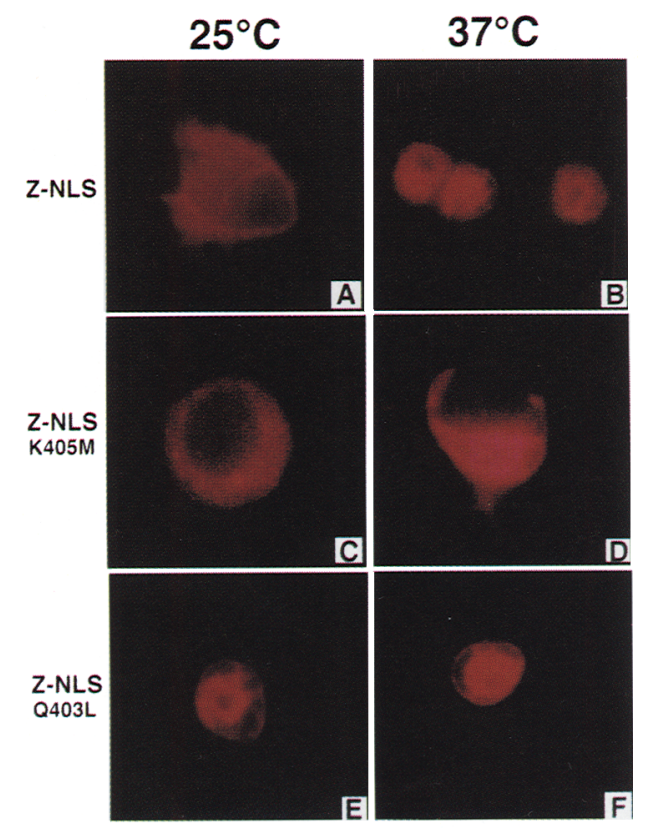

Figure 6. Analysis of $\beta$-galactosidase-NLS fusions. $(A-F)$ Immunofluorescence micrographs of wild-type NLS (Z-NLS), K405M-NLS (Z-NLSK405M), and Q403L-NLS (Z-NLSQ403L) fusions to $\beta$-galactosidase are presented. Conditions for cell transfection and staining are the same as described in the legend for Fig. 4.
Z-NLS (wild-type NLS sequence) is primarily cytoplasmic when expressed at low levels in nonshocked cells (Fig. 6A). If Z-NLS was expressed in cells at high levels, a partial or total nuclear localization of the fusion was observed in the nonshocked cells (data not shown). Z-NLS was, however, always localized within nuclei of heat-shocked cells (Fig. 6B). The fusion Z-NLS K ${ }_{405}$ to $M$ was detected exclusively in the cytosol of either nonshocked or heat-shocked cells (Fig. 6C,D), even at high levels of protein expression. The fusion Z-NLS $Q_{403} \mathrm{~L}$ showed stress-independent constitutive nuclear localization. Although Z-NLS $\mathrm{Q}_{403} \mathrm{~L}$ was largely localized in the nucleus in the nonshocked cells, there were some examples where the fusion protein was evenly distributed between the cytoplasm and nucleus (data not shown). Usually, however, the number of cells with exclusive nuclear staining was significantly greater than those evenly distributed throughout the cell. The overall staining patterns observed with these three fusion proteins indicate that the region between residues 393 and 424 contains sufficient sequence information to regulate stress-dependent nuclear translocation.

\section{DNA binding and subcellular fractionation of deletion mutants}

DNA binding and subcellular fractionation analysis of the deletion mutants was performed by also regulating their expression with the metallothionein promoter. Expression was induced with $1 \mathrm{mM} \mathrm{CuSO}_{4}$ for 1-, 2-, and 3-hr time periods. The cells were fractionated into nuclear and cytosolic fractions and subjected to DNAbinding analysis, Western blotting, and PhosphorImager analysis as described in Materials and Methods. Increasing levels of wild-type exogenous $\mathrm{dHSF}(\mathrm{dH}-\mathrm{WT}$ ) results in increasing levels of DNA-binding activity in the nuclear fraction $(\mathrm{Nu})$ of nonshocked $(\mathrm{n})$ cells (Fig. 7A). In addition, higher levels of dHSF are observed in the nuclear fraction of nonshocked cells. Prolonged expression also results in significant increase in the levels of dHSF present in the cytosolic (C) fractions of nonshocked cells. Despite this significant increase in cytosolic levels, the dHSF does not bind DNA in the cytosolic fraction. Heat shock (h) results in an essentially complete transport of the dHSF into the nucleus. PhosphorImager quantitation of the DNA-binding analysis is shown in the adjacent histograms (Fig. 7A-C). CN represents the levels of DNA binding activity observed in the cytosolic fraction of nonshocked cells. Similarly, $\mathrm{CH}$ refers to levels of DNA binding in the cytosolic fractions of heat-shocked cells. DNA-binding activity in the nuclear fractions of nonshocked (NN) and heatshocked $(\mathrm{NH})$ are also presented in the histogram. Only in the nuclear fractions are significant levels of DNAbinding activity observed when wild-type dHSF is expressed.

These results suggest that a correlation may exist between subcellular localization and DNA-binding activity of dHSF. For this reason we examined the potential role of the NLS on the DNA-binding activity of the dHSF 
A
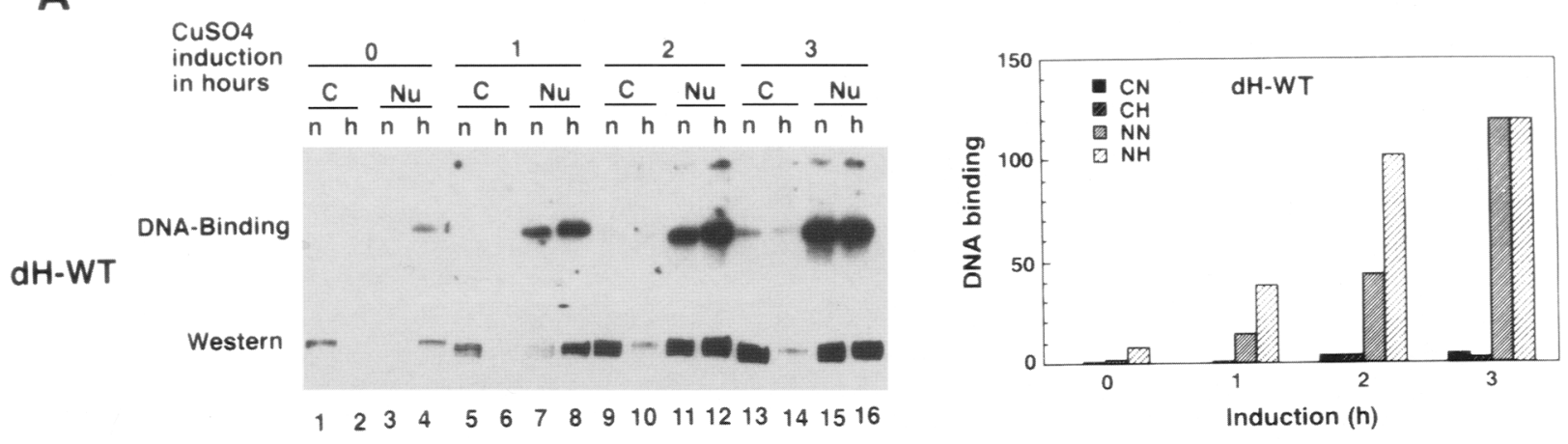

B

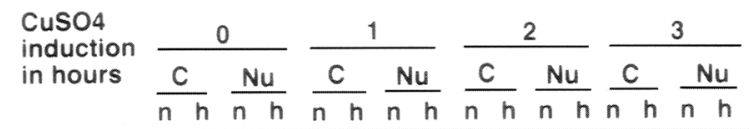

$\Delta$ NLS

DNA-Binding
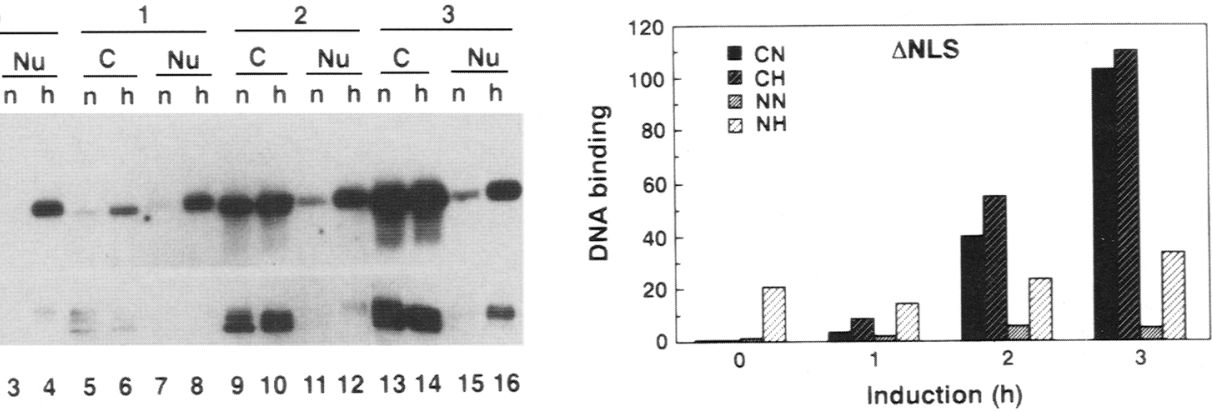

C

\section{CuSO4} induction in hours

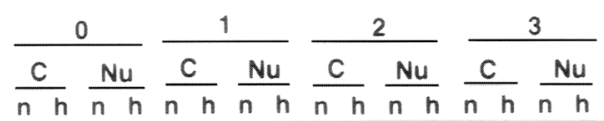

$\triangle 3 h$

DNA-Binding
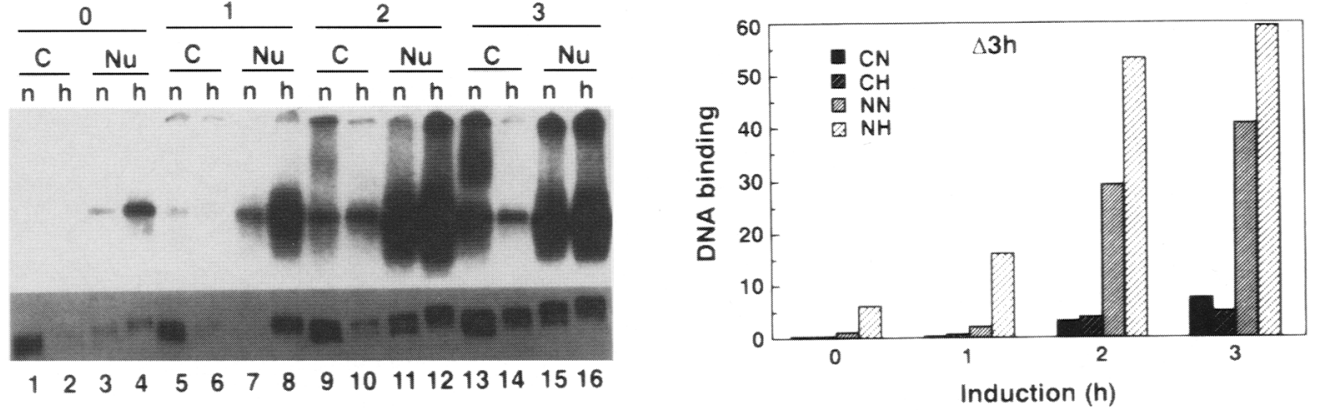

Figure 7. Analysis of wild-type dHSF (dH-WT), NLS-deleted, and 3h-deleted forms of dHSF expression levels on subcellular distribution and DNA binding. (A) Drosophila SL2 cell line carrying stably integrated cDNA encoding dHSF under control of the Drosophila metallothionein promoter was incubated with $1 \mathrm{mM} \mathrm{CuSO}_{4}$ for indicated times in hours. DNA-binding activity (DNA) and subcellular distribution (Western) of HSF was analyzed in the cytosol $(\mathrm{C})$ and nuclear $(\mathrm{Nu})$ extracts of the nonshocked $(\mathrm{n})$ and heat-shocked (h) cells. (CN) Cytosol nonshock; (CH) cytosol heat-shock; (NN) nuclear nonshock; (NH) nuclear heat-shock. (B) Analysis of the DNAbinding activity and subcellular distribution of $\triangle$ NLS, a dHSF mutant in which the nuclear localization is deleted in stably transformed SL2 cells. The analyses shown in this panel is the same as in $A$. (C) Analysis of the DNA-binding activity and subcellular distribution of $\Delta 3 \mathrm{~h}$, a dHSF mutant in which the LIR is deleted in stably transformed SL2 cells. The analysis is as described for $A$ and $B$. To the right of $A-C$, the PhosphorImager quantitation of gel shifts analyses is presented as histograms.

also expressed under the same conditions. Western analysis shows that the $\triangle \mathrm{NLS}$ mutant remains in the cytosol regardless of its expression level (Fig. 7B). This is true whether growing under normal conditions or heatshocked. Surprisingly, the $\triangle$ NLS present in these cytosolic fractions binds HSE with high affinity regardless of whether the cells are heat-shocked. In addition, $\Delta$ NLS present in nonshocked and heat-shocked cytosolic extracts binds DNA even at low levels of expression after only $1 \mathrm{hr}$ of $\mathrm{CuSO}_{4}$ induction. Also, there is no significant differ- ence between the overall DNA-binding activities of nonshocked and heat-shocked extracts measured at low or high levels of $\triangle N L S$ expression (see Fig. $7 \mathrm{~B}$, histogram of $\triangle$ NLS). Taken together, these observations suggest that the NLS regulates nuclear entry and DNA binding.

Previous studies, however, have suggested that the conserved carboxy-terminal LIR (cLIR) regulates the DNA binding of the HSF (Rabindran et al. 1993). Therefore, we examined the DNA-binding activity of a cLIR deletion mutant $(\Delta 3 h)$ in this expression system. Analy- 
sis of the DNA-binding properties and subcellular distribution of the $\Delta 3 \mathrm{~h}$ mutant at increasing levels of expression shows that the subcellular distribution of $\Delta 3 \mathrm{~h}$ is properly regulated when the cells are induced with $\mathrm{CuSO}_{4}$ for 1 and $2 \mathrm{hr}$ (Fig. $7 \mathrm{C}$ ). When the cells were induced for $3 \mathrm{hr}$, a significant amount of the protein is detected in the nuclear fraction of normally growing cells (Fig. 7C, lane $3 \mathrm{Nu}$ ). The cytosolic fractions of all nonshocked cells expressing $\Delta 3 \mathrm{~h}$ show a low level of DNA-binding activity. However, there is a large increase in DNA-binding activity when the mutant is present in the nuclear fractions (Fig. 7C, histogram $\Delta 3 \mathrm{~h}$ ). A quantitative comparison of the DNA-binding activities of $\Delta 3 \mathrm{~h}$ in the cytosolic and nuclear fractions shown in the histogram illustrates that $\Delta 3 \mathrm{~h}$ in the nuclear fraction of heat-shocked cells binds 15- to 38-fold greater to the HSE compared with $\Delta 3 \mathrm{~h}$ in the cytosolic fraction of nonshocked cells (Fig. 7C, cf. CN and NH). This demonstrates that the $\Delta 3 \mathrm{~h}$ mutant responds to heat shock in a manner similar to the dH-WT. High levels of $\Delta 3 \mathrm{~h}$ expression result in constitutive nuclear entry of a fraction of the expressed factor similar to that of wild-type dHSF (Fig. 7A). In both cases, the factors bind DNA with high affinity (Fig. 7A,C). The level of DNA-binding induction of $\Delta 3 \mathrm{~h}$ is lower than that of the $\mathrm{dH}-\mathrm{WT}$ by a factor of two (as determined by PhosphorImager analysis). Otherwise, the $\mathrm{dH}-\mathrm{WT}$ and $\Delta 3 \mathrm{~h}$ mutant respond to heat shock and overproduction essentially identically.

Comparison of the oligomeric states of $d H-W T, \Delta 3 h$, and $\triangle N L S$

Trimerization of HSF in response to heat shock is thought to be an important step in the regulation of its DNA binding activity (Peteranderl and Nelson 1992; Westwood and Wu 1993; for review, see Sorger 1991; Voellmy 1994). Therefore, we determined whether deletion of either the NLS or cLIR alters the oligomeric state of dHSF in an effort to explain the effects observed on DNA binding. The oligomeric state of the wild-type $\mathrm{dHSF}, \Delta 3 \mathrm{~h}$, and $\Delta \mathrm{NLS}$ was determined by gel filtration chromatography. In the analysis of $\mathrm{dH}-\mathrm{WT}$ and $\Delta 3 \mathrm{~h}$, we employed cytosolic nonshocked and nuclear heatshocked fractions of cells that were induced for $3 \mathrm{hr}$ with $\mathrm{CuSO}_{4}$. In the case of $\Delta \mathrm{NLS}$, the cytosolic nonshocked and the cytosolic heat-shocked fractions were assayed, because this mutant does not enter the nucleus. The extracts were fractionated on a Superdex 200 gel filtration column, and the expressed dHSFs were separated from the endogenous dHSF by $\mathrm{Ni}$-agarose chromatography in the presence of $3 \mathrm{~m}$ guanidine hydrochloride (the expressed factors all have polyhistidine tags; see Materials and Methods). Results of the Western analysis on the
Figure 8. Analysis of the oligomeric state of expressed wild-type dHSF (dH-WT), $\Delta \mathrm{NLS}$, and $\Delta 3 \mathrm{~h}$ by gel filtration chromatography on a Superdex 200 HR 10/30 column. (A) Analysis of the oligomerization state of $\mathrm{dH}-\mathrm{WT}$ in the cytosolic fraction of nonshocked (NS) cells and in the nuclear fraction of heat-shocked (HS) cells. (B) Similar analysis is shown for the $\triangle$ NLS mutant in the cytosolic fraction of nonshocked (NS) cells. (C) Similar analysis for the $\Delta 3 \mathrm{H}$ mutant, for both nonshocked cytosolic material as well as heat-shocked nuclear proteins. All of the extracts were derived from cells induced with $\mathrm{CuSO}_{4}$ for $3 \mathrm{hr}$ to express the exogenous dHSF. Fractions collected $(0.5 \mathrm{ml})$ and analyzed by Western blot (Western). The elution profiles are shown along with protein molecular weight (MW) standards as indicated at top: thyroglobulin (MW 669,000), ferritin (MW $440,000)$, human IgG (MW 150,000). DNA binding of $\Delta$ NLS and $\Delta 3 \mathrm{~h}$ proteins present in the gel filtration fractions was examined by gel shift analysis (DNA).
A

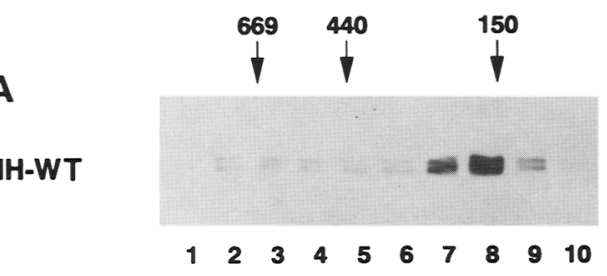

B

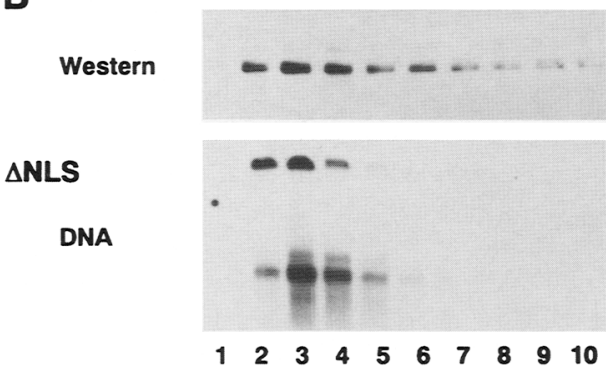

C

Western

$\Delta 3 h$

DNA

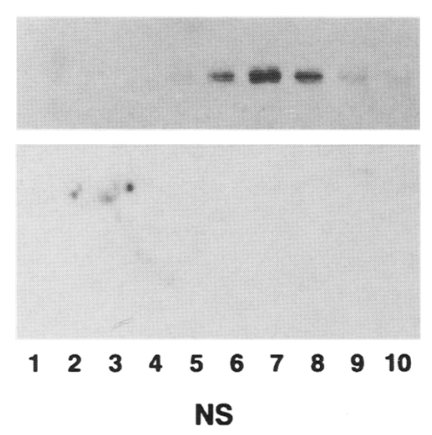

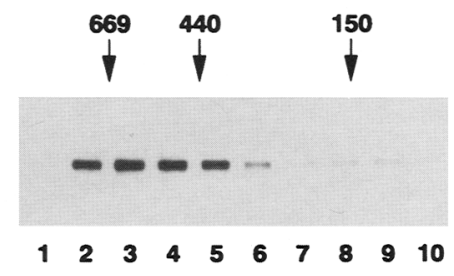

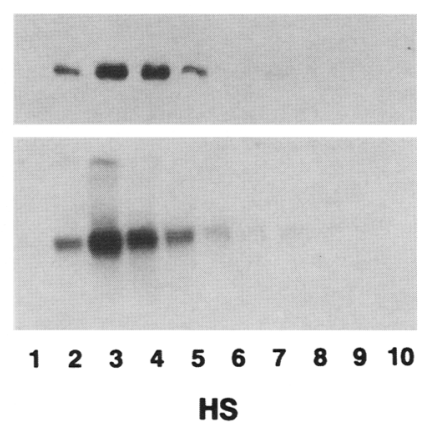


column fractions are presented in Figure 8. Wild-type dHSF present in the cytosol of the nonshocked cells chromatographs in the molecular weight (MW) range of $150 \mathrm{kD}$ consistent with a monomeric form (Fig. 8A, left, lanes 7-9). Wild-type dHSF in the nuclear fraction of the heat-shocked cells chromatographs with a significantly higher apparent MW consistent with a multimeric form of the factor (Fig. 8A, right, lanes 2-5).

The cytosolic fraction of nonshocked cells expressing $\Delta$ NLS was analyzed and shown in Figure 8B. The $\Delta$ NLS chromatographs at the same high $\mathrm{MW}$ range as wild-type dHSF present in the nuclear fraction, consistent with a multimeric form (left, lanes 2-4). The DNA-binding activity in these fractions was also monitored. As shown in Figure $8 \mathrm{~B}$, there is significant HSE binding activity in these fractions (right, lanes 2-4). The chromatographic behavior of the $\triangle$ NLS in the cytosolic fraction of the heat-shocked cells is the same as in the cytosolic fraction of nonshocked cells (data not shown).

The $\Delta 3 \mathrm{~h}$ mutant present in the cytosol of nonshocked cells fractionates at a MW range consistent with a monomeric factor (Fig. 8C, left, lanes 6-9). The DNA-binding activities in these fractions was also monitored and is shown in Figure 8C (left). There was no apparent HSE binding activity of $\Delta 3 \mathrm{~h}$ in these fractions. The $\Delta 3 \mathrm{~h}$ present in the nuclear fraction derived from heat-shocked cells migrates at a MW similar to the wild-type dHSF present in the nuclear fraction of heat-shocked cells. The $\Delta 3 \mathrm{~h}$ in these fractions binds the HSE with high affinity (Fig. 8C, right, lanes 2-5).

In summary, deletion of the cLIR ( $\Delta 3 \mathrm{~h}$ construct) does not cause constitutive oligomerization of the dHSF in the cytosol under normal growth conditions. Thus, oligomerization of $\Delta 3 \mathrm{~h}$ is regulated normally. However, deletion of the NLS region results in constitutive oligomerization of the factor in the cytosol of nonshocked cells. This suggests that the NLS region plays an important role in the regulation of dHSF oligomerization.

\section{Single amino acid substitutions in the NLS result in constitutive oligomerization and DNA binding of dHSF}

To further confirm that a functional NLS is required for the proper regulation of dHSF, we examined the DNAbinding properties of three selected point mutations within the NLS. The first mutation examined was the sole member of the class one mutation that contained three amino acid substitutions within the NLS region (LRR: Q399L, K400R, L404R; see above). As described earlier, these mutations do not have a deleterious effect on normal NLS function. The subcellular distribution of this mutant in the cytosolic and nuclear fractions of nonshocked and heat-shocked cells are comparable to those of wild-type dHSF (data not shown). In addition, this mutant binds to the HSE only when present in the nuclear fraction (data not shown).

The next mutations tested were those in which nuclear entry was disrupted (K405M or L404P). K405M is detected only in the cytosolic fractions of the non- shocked or heat-shocked cells (Fig. 9A, lanes 5,6,9, $10,13,14)$. The K405M mutant present in these fractions binds DNA constitutively with high affinity (Fig. 9A). A quantitative analysis of DNA-binding activities show that $\mathrm{K} 405 \mathrm{M}$ binds the HSE with similar affinities when derived from either nonshocked or heat-shocked cells (Fig. 9A, histogram K405M). The subcellular distribution and DNA-binding activities of L404P mutant are very similar to $\mathrm{K} 405 \mathrm{M}$, indicating that single amino acid substitutions can disrupt NLS function just as well as larger deletions (Fig. 9B).

In addition to mutations that block stress-dependent nuclear entry, we examined a mutant that constitutively enters the nucleus (Q403L). This mutant was found to reside exclusively in the nuclear fractions of both nonshocked and heat-shocked cells (Fig. 9C, lanes $7,8,11,12,15,16)$. It is important to note that the amount of dHSF seen in the cytosolic fraction of the nonshocked cells remains constant throughout the time periods examined (Fig. 9C, lanes 1,5,9,13). The DNA-binding activity of Q403L was equally strong in the nuclear fractions of nonshocked and heat-shocked cells (Fig.9C, Q403L). These observations suggest that the NLS region is necessary for both the regulation of dHSF localization and DNA binding in response to heat shock.

The oligomeric states of LRR, K405M, L404P, and Q403L were analyzed by gel filtration chromatography using Superdex 200. For LRR, a cytosolic fraction from nonshocked cells after 3 -hr $\mathrm{CuSO}_{4}$ induction was compared with the corresponding nuclear heat-shocked fraction (data not shown). As expected, the cytosolic LRR chromatographs in the MW range of a monomeric form; in heat-shocked cells the LRR chromatographs in the MW range consistent with an oligomeric form of the factor (data not shown). For K405M and L404P, the oligomerization states in the cytosolic fractions of nonshocked and heat-shocked cells were compared. K405M and L404P chromatograph in a MW range of a higherorder oligomeric structure (Fig. 9D). Adopting a higher order oligomeric structure is required for efficient DNA binding. For Q403L, the Superdex 200 fractions from nuclear nonshocked and heat-shocked extracts were analyzed (Fig. 9D). Q403L chromatographs in the high MW range when derived from both nonshocked and heatshocked cells (Fig. 9D, Q403L, lanes 2-4 of NS and HS panels). This result demonstrates that once the dHSF enters the nucleus, even under normal growth conditions, it oligomerizes and can bind DNA.

\section{Discussion}

Regulation of the stress response in eukaryotes is a complex multistep process. In Drosophila and mammals it includes nuclear transport, oligomerization, DNA binding, and possibly specific phosphorylation or dephosphorylation of the HSF (Clos et al. 1990; Baler et al. 1993; Sarge et al. 1993; for review, see Voellmy 1994; C.S. Parker, unpubl.). All of these events occur in a rapid synchronous fashion that leads to the activation of the HSF allowing $h s p$ genes to be transcribed. To define the do- 
A

CuSO4

induction

in hours

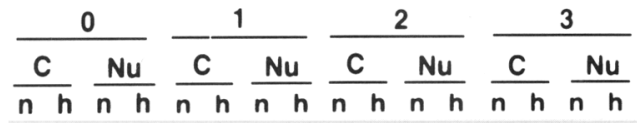

K405M

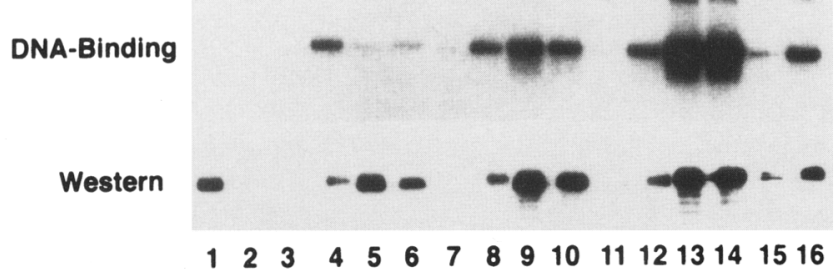

B

L404P

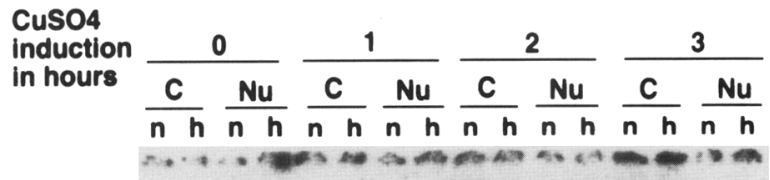

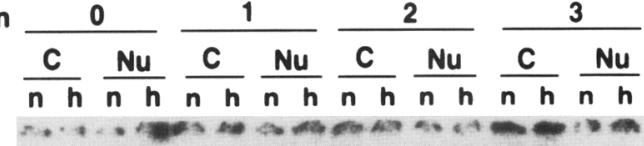

DNA-Binding

-

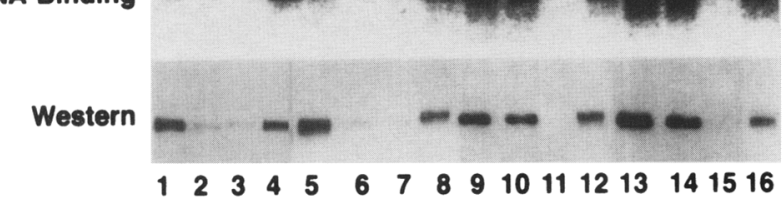

C

Q403L

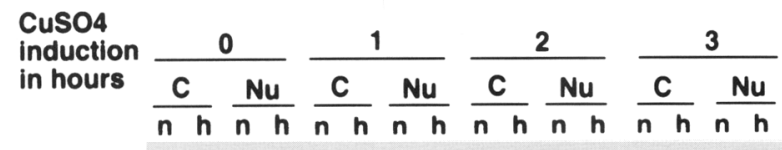

DNA-Binding

$$
n
$$

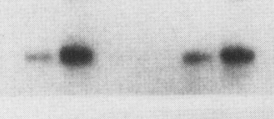

Western
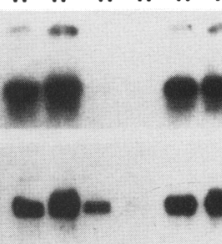
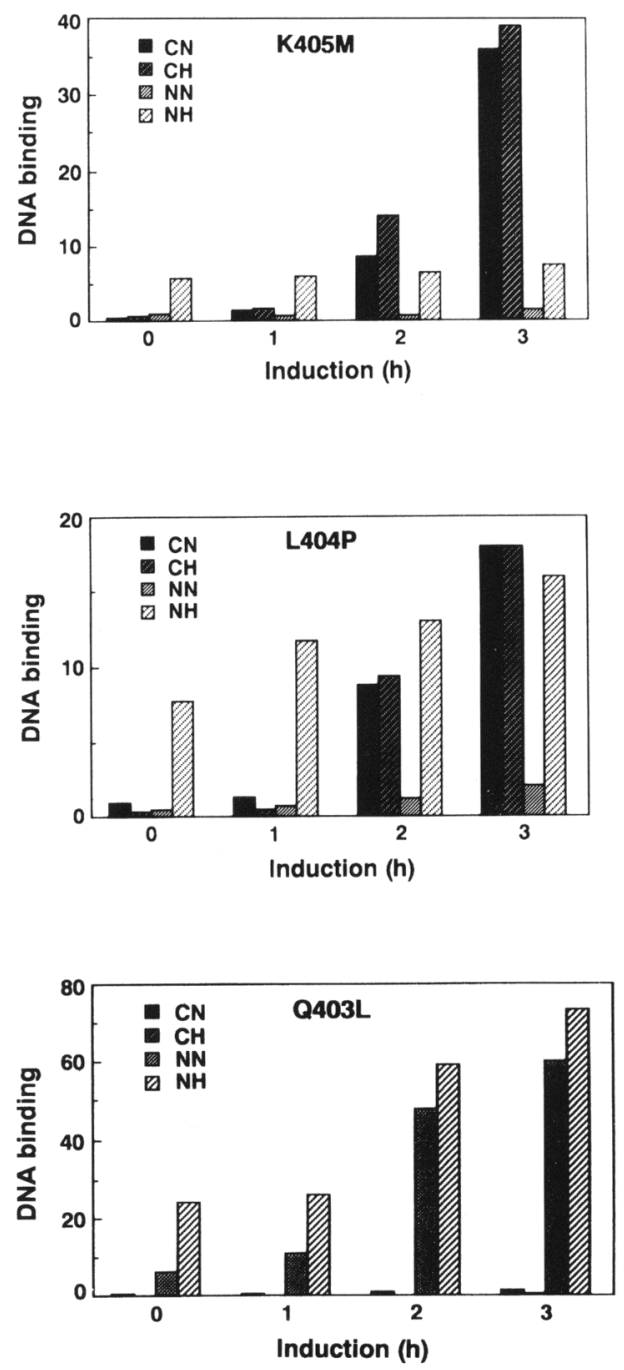

D

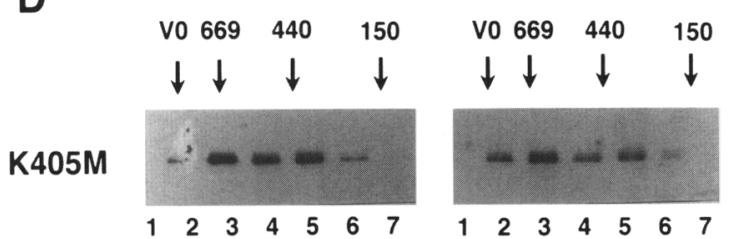

Figure 9. Analysis of the DNA-binding activity and subcellular distribution of dHSFs containing single point mutations in stably transformed SL2 cells. The general format of the data presented in this figure follows that presented in Fig. 6. $(A-C)$ Results for dHSFs containing single point mutations. Mutation in each case is indicated by a single-letter amino acid code. The first letter indicates the wild-type residue, the number shows the position, and the last letter indicates the mutant residue. (D) Analysis of the oligomeric state of expressed dHSFs containing single point mutations within the NLS was performed by gel filtration chromatography. The oligomeric state of mutants $\mathrm{K} 405 \mathrm{M}$ and L404P were analyzed in extracts of cytosolic nonshocked (NS) and cytosolic heat-shock (HS) extracts, and
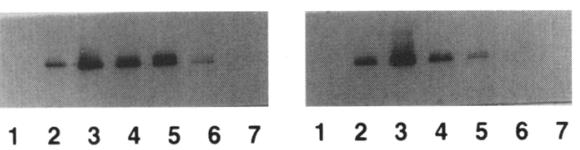

Q403L
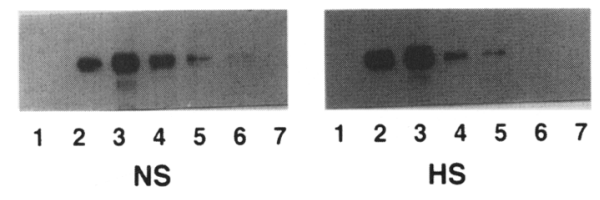
for Q403L in extracts of cytosolic nonshocked (NS) and nuclear heatshocked (HS) of cells incubated with $1 \mathrm{mM} \mathrm{CuSO}_{4}$ for $3 \mathrm{hr}$ by gel filtration chromatography as described in the legend for Fig. 7. The elution profiles are shown along with protein MW standards as indicated at the top: thyroglobulin (MW 669,000), ferritin (MW 440,000), human IgG (MW $150,000)$. mains of the dHSF that are involved in this regulatory pathway, initial studies employed transient transfection studies with mutant proteins expressed at high levels. We found that this method was unreliable as overexpres- 
sion led to nuclear entry in the absence of stress. To circumvent this problem the regulable Drosophila metallothionein promoter was used to determine the domains of the dHSF involved in the various steps of stressdependent HSF activation.

High levels of dHSF expression with either the strong actin $5 \mathrm{C}$ promoter or long periods of induction of the metallothionein promoter with $\mathrm{CuSO}_{4}$ lead to nuclear entry in the absence of stress. These observations suggest that there is a threshold level of dHSF that can be sequestered in the cytoplasm. Once the factor is expressed beyond this threshold level, nuclear entry occurs. While the factor is present within the cytosol it remains as a monomer not capable of binding DNA. Once in the nucleus, regardless of the amount of dHSF, it will adopt a higher-order structure (oligomer) and bind DNA. These results demonstrate that depending upon the cellular stress conditions, dHSF has a fixed location in the cell. Furthermore, the subcellular location of the factor seems to be crucial for its DNA-binding activity. The correlation of the oligomeric state, DNA-binding activity, and subcellular location for the dHSF suggests that a common mechanism regulates all three phenomena.

The fact that overexpression of dHSF results in constitutive nuclear entry of some of the factor suggests that dHSF is under negative control in the cytosol. It is possible that cytosolic inhibitory factors, whose amount is limited, may associate with dHSF to retain it in the cytosol in an inactive monomeric state in nonstressed cells. One curious feature of the cytosolic sequestration of the dHSF is that the capacity of the cytosol to sequester dHSF increases with increasing levels of dHSF expression. This leads to the possibility that dHSF itself is involved in the regulation of the expression of some or all components of the inhibitory mechanism. Several reports have suggested that heat shock proteins might be involved in the regulation of HSF activity (Voellmy 1994 and references therein). Although there is no evidence presented here, elevated levels of dHSF that force nuclear entry might in turn lead to an increase in heat shock protein transcription and synthesis. Clearly isolation and identification of the cytosolic sequestering and inhibiting components will be of great importance in understanding the mechanism by which stress activates the dHSF.

\section{Sequences of dHSF involved in the regulation of oligomerization and DNA binding are contained within a novel NLS}

It is apparent that oligomerization of dHSF is a prerequisite step for DNA binding because only oligomeric forms of dHSF bind to the HSEs with high affinity. The mechanism by which monomer-to-oligomer transition occurs, however, is not yet understood. In one report, it was shown that deletion of the cLIR in human and Drosophila HSF results in constitutive oligomerization for each factor (Rabindran et al. 1993). In those experiments, however, the effects of overexpression of dHSF on oligomerization and subcellular distribution of dHSF were not taken into account. The report suggested that an intramolecular interaction between cLIR and the oligomerization domain would stabilize the monomeric state of dHSF (Rabindran et al. 1993). If this were the case then the oligomeric state of the HSF should be independent of its concentration unless some other cofactor was required to stabilize this putative interaction. We note that recombinant dHSF (expressed in bacteria) is trimeric (our unpublished observations); this suggests that the monomer formation requires additional components that are not present in E. coli. Our observations demonstrate that the oligomeric state of wild-type dHSF corresponds to its subcellular location regardless of the level of expression. dHSF present in the cytosol is always monomeric and cannot bind DNA; that present in the nucleus is always found in a higher-order structure that can bind DNA.

The domain responsible for both the localization and oligomerization of dHSF is a novel NLS. We did not observe a significant role of the conserved third helical region (CLIR) in this process, however. In this report we demonstrate that if wild-type or various deletions of $\mathrm{dHSF}$, including $\Delta 3 \mathrm{~h}$, are expressed in cells at high levels, then nuclear entry occurs and DNA binding is observed only in the nuclear fractions in nonshocked cells. Our data clearly demonstrate that $\Delta 3 \mathrm{~h}$ goes through the same regulatory pathway as wild-type dHSF with regard to the regulation of oligomerization and DNA binding. Therefore, deletion of cLIR does not cause constitutive oligomerization and DNA binding of the dHSF.

In a more recent study it was shown, using a heterologous system, that there are at least three hydrophobic repeats (LZ1, LZ2, and LZ3) that are involved in the regulation of human HSF (hHSF) oligomerization (Zuo et al. 1994). We cannot directly compare our observations of the dHSF regulation in the SL2 cells with those of the hHSF observed in the Xenopus oocytes because of the heterologous nature of the system used. It would be interesting to see whether mutations in the LZ regions of hHSF that caused the constitutive oligomerization of the factor in the Xenopus oocytes would have a similar effect on the regulation of the factor in human cells. At this point, however, we cannot rule out the possibility that the regulatory pathway that we describe may be a Drosophila-specific mode of regulation. Because the cLIR is one of the few sequences conserved between the vertebrate and Drosophila factors, it remains a reasonable proposition that the cLIR is important for some aspect of dHSF regulation or transcription activity.

The analysis of wild-type dHSF in SL2 cells suggested a close correlation between the subcellular localization and the oligomeric state of the factor. As we further explored this relationship we found that deletion or lossof-function mutations in the NLS resulted not only in the disruption of the nuclear entry, but also in constitutive oligomerization and high-affinity HSE binding in the cytosol of nonshocked cells. This observation suggests that the NLS plays a central role in the activation process of dHSF. Single amino acid substitutions (K405M, for example) within the NLS also caused the disruption of nuclear entry and constitutive DNA bind- 
ing by dHSF. Thus, constitutive oligomerization of $\triangle$ NLS is probably not attributable to conformational changes resulting from the mutation, but rather is related to a mechanism regulating the activation process of dHSF. Further, single point mutations also caused the opposite effect (Q403L) and allowed constitutive nuclear entry in the absence of stress. This effect was independent of the levels of expression, leading to the possibility that an interaction with a cyotsolic inhibitor was abolished. The NLS sequence and mutation results are presented in summary form in Figure 10A.

It is both interesting and somewhat surprising that the oligomeric state of dHSF is controlled by an NLS. It is possible that the NLS regulates the oligomeric state of $\mathrm{dHSF}$ via a direct interaction with other regions of $\mathrm{dHSF}$, for example, the oligomerization domain. A more likely possibility is that there is an interaction with an acces- sory factor (inhibitor) that prevents the dHSF from entering the nucleus and oligomerizing at the same time. This accessory factor may in turn facilitate an interaction with the oligomerization domain by bridging the two domains or stabilizing a direct interaction. The only region of dHSF that, when deleted, caused constitutive oligomerization of dHSF in the cytosol was the NLS. It is likely then that any putative inhibitory factors would interact with the NLS. This interaction would not only mask the NLS from the exposure to nuclear targeting proteins, but also maintain dHSF in a monomeric conformation. It is certainly possible that the putative factor could interact with other regions of dHSF in addition to the NLS. However, it seems that an essential interaction regarding the regulation of oligomerization occurs through the NLS.

The amino acid sequence composition of the NLS in-
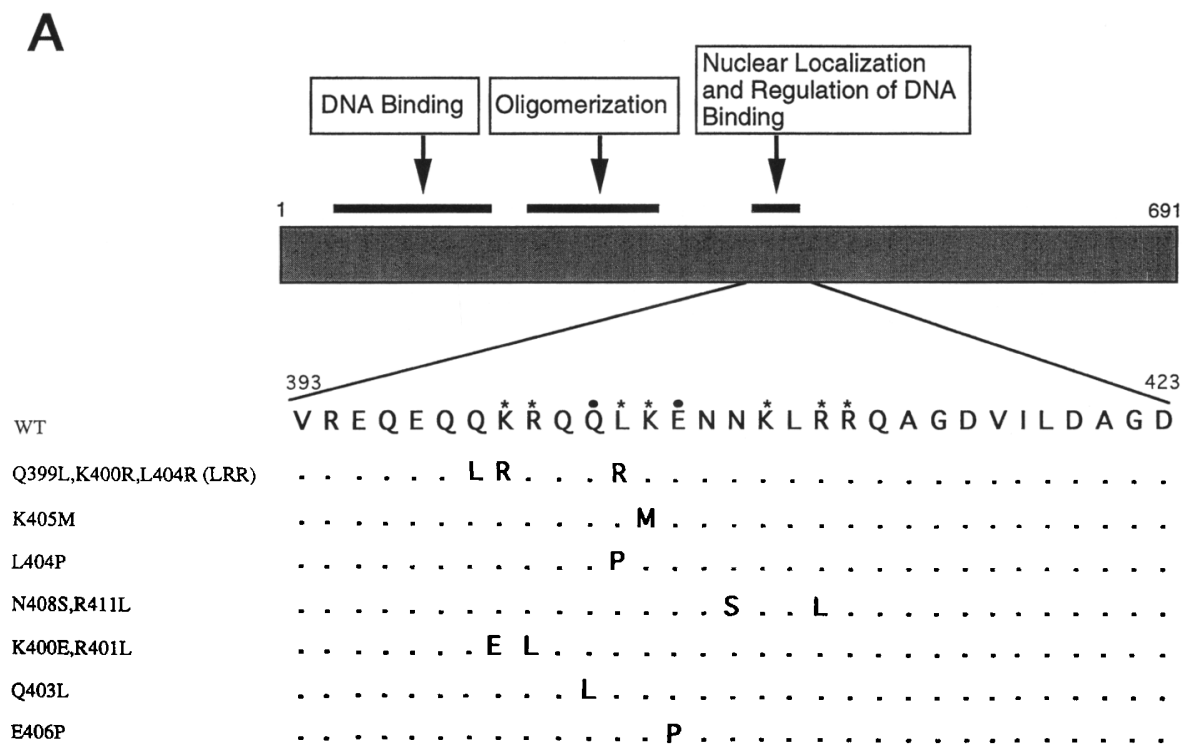

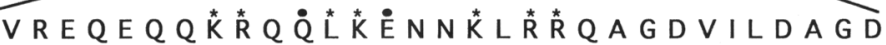

$\frac{\text { Locallzation }}{25^{\circ} \mathrm{C} \quad 37^{\circ} \mathrm{C}} \frac{\text { DNA Binding }}{25^{\circ} \mathrm{C} \quad 37^{\circ} \mathrm{C}}$

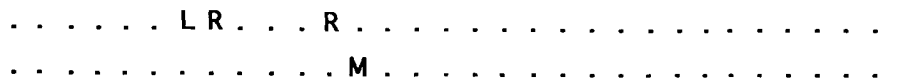

cytrnu nu - +

Q399L,K400R,L404R (LRR)
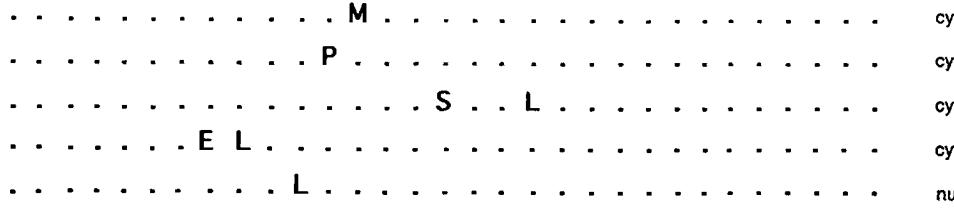

cyt nu - +

cyt cyt ++

cyt cyt ++

cyt cyt ++

cyt cyt ++

E406P

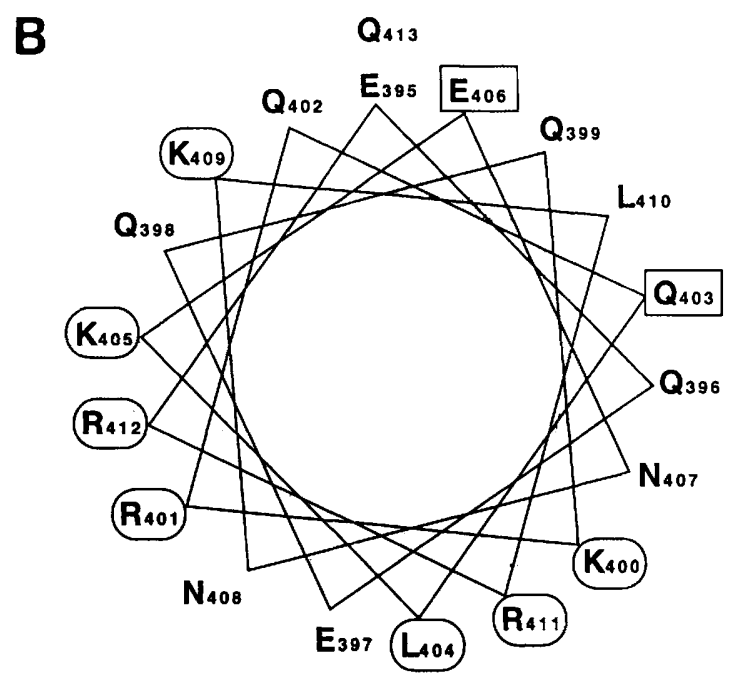

Figure 10. (A) Functional domains and summary of the mutational analysis of the NLS. $\langle B|$ Superimposition on a helical wheel with NLS amino acids positioned on it. Amino acids that, when mutated, disrupted nuclear entry are enclosed in round boxes, and those amino acids that, when mutated, resulted in constitutive nuclear entry of the dHSF are enclosed in square boxes. 
dicates that it belongs to the bipartite NLS family (Dingwall and Laskey 1991). This motif consists of a short stretch of two or three basic amino acids ( $\mathrm{K}$ and $\mathrm{R}$ ), followed by any 10 amino acids and a second short stretch of basic amino acids (usually in combinations of two or three Ks and Rs). A Chou-Fasman hydrophobicity-hydrophilicity prediction of the entire dHSF sequence suggests a strong probability of an $\alpha$-helical secondary structure in the NLS region (our unpublished data). Computer modeling of this sequence as an $\alpha$-helix shows that it is an amphiphatic helix (see Fig. 10B). On one face of the helical cylinder basic residues are clustered, resulting in a positively charged surface. On the other side of the helical cylinder are glutamine and glutamic acid residues resulting in a somewhat negatively charged face. Our mutational analysis showed that substitutions of the lysine or arginine groups on the positively charged face with other residues resulted in the disruption of nuclear entry and constitutive oligomerization of dHSF in the cytosol (see Fig. 10A), whereas substitution of Q403 on the negatively charged face resulted in constitutive nuclear entry. It is conceivable that each surface plays a unique role in the regulation of nuclear entry and oligomerization. The lysine-arginine-rich side could be the binding site for a component of the nuclear targeting machinery, and the Q-E-rich face of the helix would be the recognition site for the putative inhibitory factor. However, for stable and efficient inhibitor binding, the inhibitory factor might also interact with the basic residues on the K-R-rich face. This hypothesis helps to explain why mutations on the K-R-rich side resulted in constitutive oligomerization (efficient binding of the inhibitor would be impaired because of the mutations). An alternative explanation of the mutant effects would be that the repressor binds to the basic side and stabilizes an interaction of the Q-E-rich surface with the oligomerization domain; mutations on the Q-E surface disrupt this stabilization.

It is possible that the putative cytoplasmic inhibitory factor and a component of the nuclear targeting machinery compete for binding to the basic surface on the NLS. Under normal growth conditions the inhibitor can bind with higher affinity to the NLS perhaps by association with the Q-E-rich surface. Heat shock would then cause dissociation of the repressor (either enzymatically or by some other mechanism), allowing the nuclear targeting machinery to associate with the NLS. How the putative inhibitor would maintain the dHSF in a monomer conformation remains a mystery warranting the identification and isolation of the inhibitory components. The identification of these factors would also provide important new information about the heat-stress signal transduction pathway, which would in turn bring us one step closer to the identification of the receptors that sense cellular stress.

\section{Materials and methods}

Plasmids and DNA constructions

Two cDNAs for dHSF were isolated from a 0 - to 20 -hr embry- onic cDNA library by degenerate oligonucleotide screening employing a sequence present within the DNA-binding domain of the yeast HSF (C.S. Parker, unpubl.). These two cDNAs were identical except for their $5^{\prime}$ region. One cDNA is truncated at the $5^{\prime}$ end. This truncation removes 33 amino acids at the amino terminus of the HSF. The sequence of both cDNAs matches closely the published sequence for dHSF (Clos et al. 1990). Each of these cDNAs was subcloned as an EcoRI fragment into the pBluescript II SK (Stratagene) resulting in the pBSdHF (full-length cDNA) and pBSdHD33 (5'-truncated cDNA). The SalI-PstI fragment, containing dHSF cDNA, of each pBSdHFL and pBSdH $\Delta 33$ was subcloned into the SalI-PstI of the pSctgalx355GC (Rusconi et al. 1990), resulting in vectors pSctdHFL and pSctdH $\Delta 33$.

The Drosophila expression vector pPAc (Krasnow et al. 1989) was modified by inserting the double-stranded form of the oligonucleotide $15^{\prime}$-GATCGGATATCTCTAGAGAGCTCTCCGGATGGGATCCAAGGCCTACGTATAAGTAACTAAC-3') in the BamHI site. This oligonucleotide contains multiple cloning sites and three stop codons at its $3^{\prime}$ end. This vector is called pPAcO.

The $\mathrm{CuSO}_{4}$-inducible expression vector (pMtdH) was made by replacing the EcoRI-XbaI promoter fragment of the pPAcO with the Drosophila metallothionein promoter fragment (Otto et al. 1987), EcoRI-XbaI, from pHSH (a generous gift from Dr. Don Rio, University of California, Berkeley/ plasmid. The XbaISacII, which contains the $5^{\prime}$ coding region of the dHSF cDNA in the pMtdH, was replaced with the XbaI-SacII from pETHisdH, generating the vector $\mathrm{pMtHisdH}$. $\mathrm{pETHisdH}$ was constructed by subcloning of NdeI-BamHI fragment, which contains the fulllength cDNA of the dHSF, into the corresponding sites of $6 \mathrm{His}-$ pET $11 \mathrm{~d}$. In this construct the second amino acid of HSF is fused in frame to the six histidines. This allows the isolation of the factor on the Ni-agarose (QIAGEN) column.

pPAcOHyg was constructed as follows: Oligonucleotides $5^{\prime}$ CCCGGATCCAAAAAGCCTGAACTCACC-3' and $5^{\prime}$-CCCTCTAGACTATTCCTTTGCCCTCGG-3' were used to generate a PCR fragment of the hygromycin $B$ phosphotransferase gene from the pCophyg plasmid (a generous gift from Dr. Don Rio). This fragment was digested with BamHI and cloned into the BamHI-Stul of the pPAcO.

Deletions were made at the carboxyl terminus of dHSF by cutting the pSctdHL at a SphI site, which truncates the protein at Glu-589; a StuI site, which truncates the protein at Gln-536; a BspEI site, which truncates the protein at Ser-461; a AflII site, which truncates the protein at Leu-404; or an $S$ spI site, which truncates the protein at Asn-338. The SphI site was blunt-ended with mung bean nuclease and the BspEI and $A f l I I$ sites were filled in using the large fragment of DNA polymerase. The internal deletion $\Delta \mathrm{Bst}$ was made by in-frame fusion of the BspEI and Stul sites in the HSF. Each of these plasmids was then digested with $X b a I$ and the appropriate fragment was gel-purified and cloned into the $X b a \mathrm{I}-S n a \mathrm{BI}$ of $\mathrm{pPAcO}$ and pMt vectors.

The internal deletions $\Delta 3 \mathrm{~h}(\Delta 580-620), \Delta$ Saf $(\Delta 336-403)$, and $\Delta$ NLS $(393-420)$ were made using an oligonucleotide-directed loop-out method using conditions very similar to the site-directed mutagenesis system of Kunkel et al. (1987). For each internal deletion, an oligonucleotide was synthesized in which the end points of the targeted sequences were brought together: $\Delta \mathrm{h}, 5^{\prime}$-GTCCATTAGATCAGAGTCTGAGGCCATCCTGAGGAG-3'; $\triangle$ NLS, 5' -AATATCTCCAGCATCACCATGGGCGTGGTA-3'; $\triangle$ Saf, 5'-CTTGTTGTTCTCCTTAAGACCGCCAGCGGTTCC-3'. Approximately 20 picomoles of a phosphorylated oligonucleotide was annealed to $0.3 \mu \mathrm{g}$ of the singlestranded, uracil-substituted pBSdHFL in $20 \mathrm{~mm}$ Tris- $\mathrm{HCl} / \mathrm{pH}$ $8.01,2 \mathrm{~mm} \mathrm{MgCl}_{2}$, and $50 \mathrm{mM} \mathrm{NaCl}$. After annealing, 10x poly- 
merization buffer (100 mM Tris- $\mathrm{HCl}$ at $\mathrm{pH} 8.0,37.5 \mathrm{~mm} \mathrm{MgCl}_{2}$, $5 \mathrm{~mm}$ DTT, $7.5 \mathrm{~mm}$ ATP, $4 \mathrm{~mm}$ each dNTPs) was added to the reaction, as well as 10 units of T4 DNA ligase and 2 units of T4 DNA polymerase. The polymerization reaction was incubated for $15 \mathrm{~min}$ on ice followed by incubation for $2 \mathrm{hr}$ at $37^{\circ} \mathrm{C}$. The reaction was diluted to $80 \mu \mathrm{l}$ with TE (10 mM Tris at $\mathrm{pH} 8.0,2$ mM EDTA), and $20 \mu \mathrm{l}$ of that was used to transform $E$. coli strain $\mathrm{DH} 5 \alpha$. The deletion of the targeted sequence was verified by restriction digest analysis. Using restriction sites at the flanking region of the deleted sequences, the homologous regions of the HSF in expression vectors $\mathrm{pPAcO}$ and $\mathrm{pMtHis}$ were replaced. The joint points were verified by sequencing through the deleted region.

An oligonucleotide containing multiple in-frame cloning sites (BamHI, SmaI, AflII, BspEI, XhoI) was inserted into the BamHI-Xhol of pSctZ (a generous gift from Dr. S. Rusconi, University of Friebourg, Switzerland) resulting in the vector pSctZE. The pPAcoZE was constructed by ligation of the $\beta$-galactosidase $(Z)$ gene, $X b a I-X h o I$ fragment from pSctZE into the pPAcO. HSF- $\beta$-galactosidase fusions were constructed as follows: The dHSF deletions were generated by PCR and fused to the $\mathrm{Z}$ DNA in the pPacoZE vector. All $5^{\prime}$ primers contain a BamHI in-frame site and all 3' primers contain an in-frame stop codon followed by a XmaI site. PCR fragments were digested with BamHI and XmaI and cloned into the BamHI and BspEI of pPacoZE. Primers Bl (5'-CCCGGATCCTCCAGGTCGCGTTCA-3') and X1 (5'-TTTCCCGGGTTACAACTCGTG-3') were used to generate the entire dHSF coding region from the amino acids 2 to 691 including the stop codon. This fragment is called hereafter $2 \mathrm{C}$. The resulting construct is called Z-2C in Figure 4E. For Z-165C, in which dHSF from amino acids 165 to 691 is fused to $Z$, primer B2 (5'-CCCGGATCCGCCATGTCGAAG-3') and X1 were used. For Z-220C, primer 3B (5'-CCCGGATCCCAGTTCCTCATT$\left.3^{\prime}\right)$ and $\mathrm{Xl}$ were used to generate dHSF coding region from 220 to 691. For Z-360C, primer B4 (5'-CCCGGATCCGATGTCTACACA-3') and X1 were used. For Z-405C, the $2 \mathrm{C}$ fragment was digested with $A f I I I$ and $X m a I$ and ligated to the $A f I I I$ and $B s p E I$ of the pPacoZE. For Z-460C, the $2 \mathrm{C}$ fragment was digested with $B s p E I$ and $X m a I$, which was ligated into the BspEI of the $\mathrm{pPa}$ coZE. The correct orientation of this fragment was determined by restriction digest analysis. For $\mathrm{Z}-\mathrm{N} 405$ in which $\mathrm{Z}$ is fused to amino acids 2 to 405 of dHSF, the $2 \mathrm{C}$ fragment was digested with BamHI and $A f 7 I I$ and ligated into the corresponding sites in the pPacoZE. For Z-N536, 2C was digested with BamHI and StuI and ligated into BamHI and blunt-ended $\mathrm{XhoI}$ of pPacoZE. For Z-N460, the 2C was digested with BamHI and BspEI and ligated into the corresponding sites in the pPacoZE. For $\mathrm{Z}-\mathrm{N} 340$, the $2 \mathrm{C}$ was digested with BamHI and SspI and ligated into the $B a m H I$ and blunt-ended XhoI. For Z- $\Delta$ NLS, the dHSF fragment in which the NLS is deleted was generated from the $\mathrm{pPaco} \Delta \mathrm{NLS}$ using primers $\mathrm{B} 1$ and X1. To make sure that fusions are good, the joint points were sequenced and the protein products expressed in SL2 cells were analyzed by Western blot. In the case of fusions Z-NLS, Z-NLSK405M, and Z-NLSQ403L (see Fig. 6G), primers (5' -CCCGGATCCGTGCGGGAGCAG-3' and $5^{\prime}$-TTTCCCGGGTTAAATATCTCCAGC-3') were used to generate the region coding 393 to 424 of the wild type and indicated mutants of dHSF. For these fusions the entire dHSF fragments were sequenced after fusing them to $\mathrm{Z}$.

\section{Mutagenesis}

The NLS region (393 to 415 ) in the pBSdHFL was subjected to a random mutagenesis by using the oligonucleotide w10 (5'-ATCTCCTGCCXGTYGTYGTZGCXXGXTGXTCXCCXXAZGCX-
GCXGAYGCXXCXGCXGCXCCXGCTCCCGCACC-3'). For the synthesis of this oligonucleotide mixture of $X=90 \%$ $\mathrm{T}+3.3 \%$ of each $\mathrm{A}, \mathrm{C}$, and $\mathrm{G} ; \mathrm{Y}=90 \% \mathrm{C}+3.3 \%$ of each $\mathrm{A}, \mathrm{T}$, and $G$; and $Z=90 \% A+3.3 \%$ of each $C, T$, and $G$ were used to obtain a pool of oligonucleotides having mutations at the second and third position of the codon for each amino acid. The w 10 oligonucleotide was used for dsDNA synthesis by the method of Kunkel et al. (1987) as described above. After transformation of dsDNA into bacteria, single colonies were picked, plasmid DNA was isolated, and the mutagenized region was sequenced. After identification of mutations, the mutated regions were subcloned (via $B s t \mathrm{BI}$ and $B s p \mathrm{EI}$ ) into the $\mathrm{pPAcodH}$ or pMtHisdH to replace the homologous portion of the dHSF with the mutated region.

\section{Cell culture, stable and transient transfections}

D. melanogaster Schneider cell line 2 (SL2) (Schneider 1972) was maintained in SL2 cell culture media (GIBCO) supplemented with $10 \%$ heat-treated (at $65^{\circ} \mathrm{C}$ for $30 \mathrm{~min}$ ) fetal bovine serum (Hy-clone), $100 \mathrm{U} / \mathrm{ml}$ of penicillin and $100 \mathrm{U} / \mathrm{ml}$ of streptomycin. Cells were grown in Corning flasks at $25^{\circ} \mathrm{C}$ (nonshocked). For DNA transfection, $3 \times 10^{6}$ cells were seeded in 3 $\mathrm{ml}$ of medium on a $30-\mathrm{mm}$ tissue culture dish and transfected using calcium phosphate precipitates (Ausubel et al. 1992). The cotransfection cocktail contained a mixture of $5 \mu \mathrm{g}$ of the vector that contained the gene of interest and $1 \mu \mathrm{g}$ of the vector that contained the selectable marker pPacHyg. At 15-18 hr posttransfection cells were spun down, washed once with $1 \times$ PBS containing $2 \mathrm{mM}$ EDTA, washed with the complete medium, and resuspended in $3 \mathrm{ml}$ of fresh medium. After 4 days, cells were spun down and resuspend in selective medium containing hygromycin B $(200 \mu \mathrm{g} / \mathrm{ml})$. Selective medium was replaced every 5 days, and stably transformed polyclonal cell populations were isolated after 3 or 6 weeks of selection with hygromycin B. Hygromcin B was maintained routinely in the media at all times after selection.

For transient expression, cells were transfected as above, except no vector containing a selective marker gene was included in the transfection mixture. The amount of the DNA that was used for transfection is indicated in the figures. After transfection, cells were washed as above and grown for 2 days before using them for experiments.

Cells were heat shocked at $37^{\circ} \mathrm{C}$ for $30 \mathrm{~min}$ on the tissue culture dish by transferring the plates to a $37^{\circ} \mathrm{C}$ incubator.

\section{$\mathrm{CuSO}_{4}$ induction}

We have analyzed and determined the optimum induction procedure for the metallothionein promoter. Cells were induced routinely by addition of $1 \mathrm{~mm}$ of $\mathrm{CuSO}_{4}$ to the culture medium for times indicated in the figure legends.

\section{Cell staining and immunofluorescence detection}

Cells were grown at $25^{\circ} \mathrm{C}$ and subjected to heat shock as described above. Nonshocked and heat-shocked cells were fixed directly on the tissue culture dish with the $1 \times$ tissue fixative Histochoice (Amresco, Solon, $\mathrm{OH}$ ) for $15 \mathrm{~min}$ at room temperature. Fixative was removed and cells were washed three times with $1 \times \mathrm{PBS}\left(137 \mathrm{~mm} \mathrm{NaCl}, 5 \mathrm{~mm} \mathrm{KCl}, 7.5 \mathrm{mM} \mathrm{Na}_{2} \mathrm{HPO}_{4}\right)$. Cells were incubated $1 \mathrm{~min}$ in $0.1 \% \mathrm{NP}-40$ in PBS. After three PBS washes, cells were incubated with a 1:100 dilution, for detection of the endogenous HSF, or 1:1000 dilution, for detection of the expressed factors, of a mixture of four monoclonal anti-Drosophila HSF antibodies or IgG fraction of rabbit anti- $\beta$-galactosidase (Cappel, Oregon Teknika Corp., West Chester, PA), in 
$1 \%$ nonfat dry milk for $1 \mathrm{hr}$ at room temperature. After extensive washing with PBS, cells were incubated with secondary antibodies, fluorescein-conjugated goat affinity purified antimouse IgG-IgM, or rhodamine-conjugated IgG fraction goat anti-rabbit IgG (Cappel), at a dilution of 1:200 for $30 \mathrm{~min}$ at room temperature. Cells were washed four times with PBS and a drop of buffered $90 \%$ glycerol containing $2 \%$ propyl gallate was applied and a no. 1 cover slip was attached. Cells were viewed and photographed using a Zeiss Axioplan under normal phase microscopy and with UV irradiation with the aid of fluorescein- and rhodamine-specific filters. Micrographs were reproduced from slides on a sprint scan 35 (Polaroid) and printed on a Kodak XLS 8300 digital printer.

\section{Preparation of mini cytosolic and nuclear extracts}

The cytoplasmic and nuclear extracts were prepared by modifications of the procedure described by Schreiber et al. (1988): 1.5 $\mathrm{ml}$ of the cell suspension $\left(3 \times 10^{6}\right.$ cells $\left./ \mathrm{ml}\right)$ were centrifuged for $2 \mathrm{~min}$ at $3000 \mathrm{rpm}$ and washed with PBS. Cells were harvested at $3000 \mathrm{rpm}$ and resuspended in $150 \mathrm{ml}$ of hypotonic buffer (A) containing $10 \mathrm{~mm}$ HEPES at $\mathrm{pH} 7.9,10 \mathrm{~mm} \mathrm{KCl}, 0.1 \mathrm{~mm}$ EDTA, $0.1 \mathrm{mM}$ EGTA, $2.5 \mathrm{~mm} \mathrm{DTT}, 5 \mathrm{mg} / \mathrm{ml}$ of leupeptin, and $1.2 \mathrm{~mm}$ PMSF and incubated on ice for $5 \mathrm{~min}$. Then $150 \mathrm{ml}$ of buffer $\mathrm{A}$ containing $0.5 \%$ of NP-40 was added and vortexed for $10 \mathrm{sec}$. The mixture was centrifuged at $14,000 \mathrm{~g}$ for $2 \mathrm{~min}$. The cytoplasmic supernatant was transferred into a new Eppendorf tube and the nuclear pellet was washed once with $100 \mathrm{ml}$ of $0.5 \%$ NP-40 in buffer A. Each nuclear pellet was resuspended in 200 $\mathrm{ml}$ of buffer $\mathrm{C}$ consisting of $20 \mathrm{~mm}$ HEPES at $\mathrm{pH} 7.9,25 \%$ glycerol, $0.8 \mathrm{M} \mathrm{NaCl}, 100 \mathrm{~mm} \mathrm{KCl}, 0.01 \%$ triton X100, $1 \mathrm{~mm}$ EDTA, $1 \mathrm{~mm}$ EGTA, and DTT-leupeptin-PMSF as above. Samples were vortexed and incubated on ice for $15 \mathrm{~min}$, and then centrifuged at $14,000 \mathrm{~g}$ for $5 \mathrm{~min}$. The supernatant is the nuclear extract.

\section{Protein analysis: gel electromobility shift assay, Western blot}

Eight microliters of the cytoplasmic and $2 \mu \mathrm{l}$ of the nuclear extracts were used for the gel electromobility shift assay. The differences in the salt concentrations of cytosolic and nuclear extracts were adjusted by adding $2 \mu$ of buffer $\mathrm{C}$ to the gel shift reaction of the cytosolic extract, and adding $8 \mu \mathrm{l}$ of the buffer $\mathrm{A}$ to the gel shift reaction of the nuclear extract. In general the binding reactions $(30 \mu l)$ contain $0.2-0.5 \mathrm{ng}(30,000 \mathrm{cpm})$ of a radiolabeled double-stranded HSE oligonucleotide $15^{\prime}$-GCGCGCCTCGAATGTTCGCGAAAAGA-3'), $1 \mu \mathrm{g}$ of poly[(dA-T)], 1 $\mu \mathrm{g}$ poly[(dI-C)], $0.5 \mu \mathrm{g}$ salmon testis DNA, $4 \%(\mathrm{wt} / \mathrm{vol})$ Ficoll, $20 \mathrm{~mm}$ HEPES at $\mathrm{pH} 7.9,50 \mathrm{~mm} \mathrm{NaCl}, 20 \mathrm{~mm} \mathrm{KCl}, 1 \mathrm{~mm}$ EDTA, $1 \mathrm{mM} \mathrm{DTT}$, and $0.25 \mathrm{mg} / \mathrm{ml}$ of bovine serum albumin (BSA; Boehringer Mannheim) and extracts as described above. The samples were incubated on ice for $30 \mathrm{~min}$. Fifteen microliters of the mixture was loaded on a $4 \%$ polyacrylamide gel 30 acrylamide: 1 BIS acrylamide) and electrophoresed for $2-3 \mathrm{hr}$. The gel was usually prerun for $30 \mathrm{~min}$ at $20^{\circ} \mathrm{C}$ at $12 \mathrm{~V} / \mathrm{cm}$ in $0.25 \times \mathrm{TBE}$. After electrophoresis the gel was dried and exposed to X-ray film or a PhosphorImager screen (Molecular Dynamics).

The remaining $15 \mu$ l of the gel shift reactions were separated on an $8 \%$ SDS-PAGE and transferred to a nitrocellulose membrane. After blocking the nitrocellulose with $3 \%$ (wt/vol) Carnation nonfat dry milk, the blot was probed with a 1:1000 dilution of a hybridoma supernatant containing anti-Drosophila HSF. Primary antibodies were visualized by the ECL (Amersham/ method as recommended by the vendor.

\section{Gel filtration chromatography}

For analytical gel filtration chromatography, $300 \mu \mathrm{l}$ of cytosolic extract or $100 \mu \mathrm{l}$ of nuclear extract was loaded on a Superdex $200 \mathrm{HR} 10 / 30(0.5 \times 30 \mathrm{~cm}$; Pharmacia) column that was equilibrated in buffer NPO $\left[150 \mathrm{~mm} \mathrm{NaCl}\right.$ and $50 \mathrm{mM} \mathrm{Na}_{2} \mathrm{HPO}_{4}(\mathrm{pH}$ 7.0)]. The column was run at a flow rate of $0.5 \mathrm{ml}$ per minute. The void volume of this column is $\sim 6 \mathrm{ml}$. Oligomeric dHSF elutes between 6.5 and $8 \mathrm{ml}$, and monomeric HSF elutes between 8.5 and $10 \mathrm{ml}$. Fractions of $0.5 \mathrm{ml}$ or $1 \mathrm{ml}$ were collected. Proteins in each fraction either were TCA precipitated or, in the case of histidine-tagged proteins, were separated from the endogenous HSF on Ni-agarose beads (Qiagen) in the presence of $3 \mathrm{M} \mathrm{GuHCl}$. Proteins were separated on SDS-PAGE, and dHSF was visualized by Western blotting.

\section{Acknowledgments}

We thank Carol Johns for her expert technical assistance; the Caltech monoclonal antibody facility for preparing the monoclonal antibodies used in this report; and Gary Belford for his help in reproducing the micrographs from slides. T.-N.T.T. and W.C. were each recipients of a Summer Undergraduate Research Fellowship award from Caltech. This work was supported by a National Institutes of Health grant to C.S.P. (GM 47381).

The publication costs of this article were defrayed in part by payment of page charges. This article must therefore be hereby marked "advertisement" in accordance with 18 USC section 1734 solely to indicate this fact.

\section{References}

Ausubel, F.M., R. Brent, R.E. Kingston, D.D. Moore, J.G. Seidman, J.A. Smith, and K. Struhl, eds. 1992. Current protocols in molecular biology. Greene Publishing Associates/ Wiley-Interscience, New York, NY.

Baeuerle, P. and D. Baltimore. 1988. IкB: A specific inhibitor of the NF-kB transcription factor. Science 242: 540-545.

Baeuerle, P. and T. Henkel. 1994. Function and activation of NF-kB in the immune system. Annu. Rev. Immuno. 12: 141179.

Baler, R., G. Dahl, and R. Voellmy. 1993. Activation of human heat shock genes is accompanied by oligomerization, modification, and rapid translocation of heat shock transcription factor HSF1. Mol. Cell. Biol. 13: 2486-2496.

Beg, A.A. and A.S. Baldwin, Jr. 1994. The IkB proteins: Multifunctional regulators of Rel/NF-kB transcription factors. Genes \& Dev. 7: 2064-2070.

Beg, A.A., S.M. Ruben, R.I. Scheinman, S. Haskill, C.A. Rosen, and A.S. Baldwin, Jr. 1992. IkB interacts with the nuclear localization sequences of the subunits of NF-kB: A mechanism for cytoplasmic retention. Genes \& Dev. 6: 1899-1913.

Blank, V., P. Kourilsky, and I. Alain. 1992. NF-кB and related proteins: Rel/dorsal homologies meet ankyrin-like repeats. Trends Biochem. Sci. 17: 135-140.

Clos, J., J.T. Westwood, P.B. Becker, S. Wilson, K. Lambert, and C. Wu. 1990. Molecular cloning and expression of a hexameric Drosophila heat shock factor subject to negative regulation. Cell 63: 1085-1097.

Dingwall, C. and R.A. Laskey. 1991. Nuclear targeting sequences-A consensus? Trends Biochem. Sci. 16: 478-481.

Gallo, G.L., T.J. Schuetz, and R.E. Kingston. 1991. Regulation of heat shock factor on Schizosaccharomyces pombe more closely resembles regulation in mammals than in Saccharomyces cerevisiae. Mol. Cell. Biol. 11: 281-288.

Hanover, J.A. 1992. The nuclear pore: At the crossroads. FASEB J. 6: 2288-2295. 
Henkel, T., T. Machleidt, I. Alkalay, M. Kronke, Y. Ben-Neriah, and P. Baeuerle. 1993. Rapid proteolysis of IkB-a is necessary for activation of transcription factor NF-kB. Nature 365: 182-185.

Jakobsen, B.K. and H.R.B. Pelham. 1988. Constitutive binding of yeast heat shock factor to DNA in vivo. Mol. Cell. Biol. 8: 5040-5042.

Keegan, L., G. Gill, and M. Ptashne. 1986. Separation of DNA binding from the transcription-activating function of a eukaryotic regulatory protein. Science 231: 699-704.

Krasnow, M.A., E.E. Saffman, K. Kornfeld, and D.S. Hogness. 1989. Transcriptional activation and repression by ultrabithorax proteins in cultured Drosophila cells. Cell 57: 10311043.

Kunkel, T.A., D.J. Roberts, and R.A. Zakour. 1987. Rapid and efficient site-specific mutagenesis without phenotypic selection. Methods Enzymol. 154: 367-382.

Morimoto, R.I., K.D. Sarge, and K. Abravaya. 1992. Transcriptional regulation of heat shock genes. J. Biol. Chem. 267: 21987-21990.

Otto, E., J.M. Allen, J.E. Young, R.D. Palmiter, and G. Maroni. 1987. A DNA segment controlling metal-regulated expression of the Drosophila melanogaster metallothionein gene Mtn. Mol. Cell. Biol. 7: 1710-1715.

Peteranderl, R. and H.C.M. Nelson. 1992. Trimerization of the heat shock transcription factor by a triple-stranded $\alpha$-helical coiled-coil. Biochemistry 31: 12272-12276.

Picard, D. and K. Yamamoto. 1987. Two signals mediate hormone-dependent nuclear localization of the glucocorticoid receptor. $E M B O ~ J$. 6: 3333-3340.

Ptashne, M. 1988. How eukaryotic transcription activators work. Nature 335: 683-689.

Rabindran, S.K., G. Giorgi, I. Clos, and C. Wu. 1991. Molecular cloning and expression of a human heat shock factor. Proc. Natl. Acad. Sci. 88: 6906-6910.

Rabindran, S.K., R.I. Haroun, J. Clos, J. Wisniewski, and C. Wu. 1993. Regulation of heat shock factor trimer formation: Role of a conserved leucine zipper. Science 259: 230-234.

Rusconi, S., Y. Severne, O. Georgiev, I. Galli, and S. Weiland. 1990. A novel expression assay to study transcriptional activators. Gene (Amst.) 89: 211-221.

Sarge, K.D., V. Zimarino, K. Holm, C. Wu, and R.I. Morimoto. 1991. Cloning and characterization of two mouse heat shock factors with distinct inducible and constitutive DNA-binding ability. Genes \& Dev. 5: 1902-1911.

Sarge, K.D., S.P. Murphy, and R.I. Morimoto. 1993. Activation of heat shock gene transcription by heat shock factor 1 involves oligomerization, acquisition of DNA-binding activity, and nuclear localization and can occur in the absence of stress. Mol. Cell. Biol. 13: 1392-1407.

Scharff, K.D., S. Rose, W. Zott, F. Schoff, and L. Nover. 1990. Three tomato genes code for heat stress transcription factors with a region of remarkable homology to the DNA-binding domain of the yeast HSF. EMBO J. 9: 4495-4501.

Schneider, I. 1972. Cell lines derived from late embryonic stages of Drosophila melanogaster. I. Embryol. Exp. Morphol. 27: 353-365.

Schreiber, E., M. Muller, P. Matthias, and W. Schaffner. 1988 Identification of a novel lymphoid specific octamer bindingprotein (OTF-2B) by proteolytic clipping bandshift assay (PCBA). EMBO J. 7: 4221-4229.

Schuetz, T.J., G.J. Gallo, L. Sheldon, P. Tempst, and R.E. Kingston. 1991. Isolation for a cDNA for HSF2: Evidence for two heat shock factor genes in humans. Proc. Natl. Acad. Sci. 88: 6910-6915.

Sheldon, L.A. and R.E. Kingston. 1993. Hydrophobic coiled-coil domains regulate the subcellular localization of human heatshock factor 2. Genes \& Dev. 7: 1549-1558. [Corrigendum. 1994. 8: 386.]

Sorger, P.K. 1991. Heat shock factor and the heat shock response. Cell 65: 363-366.

Sorger, P.K. and H.C.M. Nelson. 1989. Trimerization of a yeast transcription activator via a coiled-coil motif. Cell 59: 807813.

Sorger, P.K. and H.R.B. Pelham. 1988. Yeast heat shock factor is an essential DNA-binding protein that exhibits temperature-dependent phosphorylation. Cell 54: 855-864.

Steward, R. 1989. Relocalization of the dorsal protein from the cytoplasm to the nucleus correlates with its function. Cell 59: 1179-1188.

Voellmy, R. 1994. Transcription of the stress signal and mechanisms of transcriptional regulation of heat shock/stress protein gene expression in higher eukaryotes. Crit. Rev. Eukaryotic Gene Exp. 4: 357-401.

Westwood, J.T. and C. Wu. 1993. Activation of Drosophila heat shock factor: Conformational change associated with a monomer-to-trimer transition. Mol. Cell. Biol. 13:34813486.

Westwood, J.T., J. Clos, and C. Wu. 1991. Stress-induced oligomerization and chromosomal relocalization of heat-shock factor. Nature 353: 822-827.

Wiederrecht, G., D. Seto, and C.S. Parker. 1988. Isolation of the gene encoding the $S$. cerevisiae heat shock transcription factor. Cell 54: 841-853.

Zuo, J., R. Baler, G. Dahl, and R. Voellmy. 1994. Activation of DNA-binding ability of human heat shock transcription factor 1 may involve the transition from an intramolecular to an intermolecular tristranded coiled-coil structure. Mol Cell. Biol. 14: $7557-7568$. 


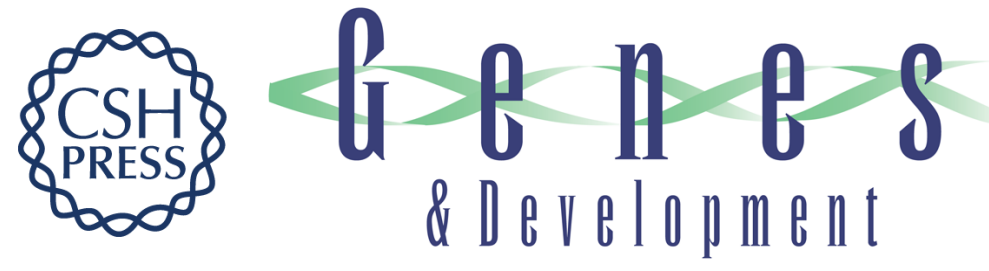

\section{Nuclear entry, oligomerization, and DNA binding of the Drosophila heat shock transcription factor are regulated by a unique nuclear localization sequence.}

E Zandi, T N Tran, W Chamberlain, et al.

Genes Dev. 1997, 11:

Access the most recent version at doi:10.1101/gad.11.10.1299

References This article cites 39 articles, 15 of which can be accessed free at:

http://genesdev.cshlp.org/content/11/10/1299.full.html\#ref-list-1

License

Email Alerting

Service

Receive free email alerts when new articles cite this article - sign up in the box at the top right corner of the article or click here.

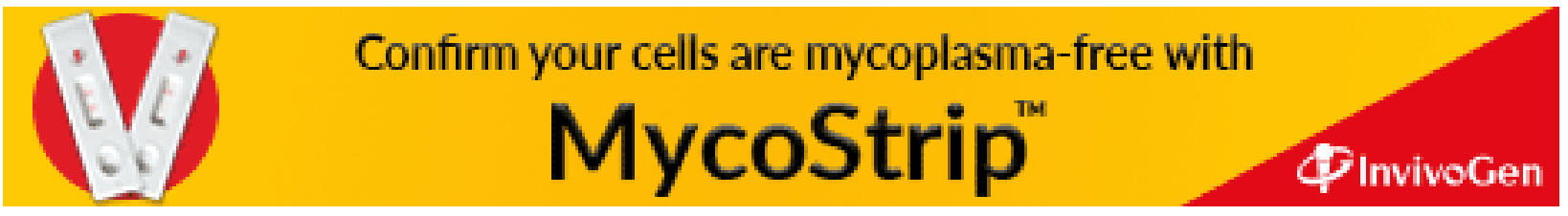

